\title{
Daily atmospheric circulation events and extreme precipitation risk in Northeast Spain: the role of the North Atlantic Oscillation, Western Mediterranean Oscillation, and Mediterranean Oscillation
}

\author{
Sergio M. Vicente-Serrano ${ }^{1}$, Santiago Beguería ${ }^{2}$, Juan I. López-Moreno ${ }^{1}$, Ahmed M. El \\ Kenawy ${ }^{1}$ and Marta Angulo ${ }^{2}$ \\ ${ }^{1}$ Instituto Pirenaico de Ecología—CSIC, Campus de Aula Dei, P.O. Box 13034, Zaragoza 50080, Spain, \\ ${ }^{2}$ Estación Experimental de Aula Dei_CSIC, Campus de Aula Dei, P.O. Box 13034, Zaragoza 50080, \\ Spain. \\ e-mail: svicen@ipe.csic.es
}

Abstract. We employed a novel method that combined probabilistic analysis and spatial modeling assisted by GIS to analyze the risk of extreme precipitation in Northeast Spain related to three atmospheric circulation configurations: the North Atlantic Oscillation (NAO), Mediterranean Oscillation, and Western Mediterranean Oscillation (WeMO). The analysis was performed at an event-based scale using data obtained from daily atmospheric circulation indices. The maximum intensity and total precipitation magnitude recorded during positive and negative circulation events were obtained from the daily records of 174 observatories between 1950 and 2006. The series of both maximum intensity and magnitude for positive and negative phases of the three atmospheric circulation indices follow a Generalized Pareto (GP) distribution. A regression-based interpolation procedure was used to generate distributed maps of GP parameters, enabling us to determine the probability of the magnitude and maximum intensity of precipitation and the quantile precipitation for any return period associated with the positive and the negative phases of the three atmospheric circulation patterns. A high spatial variability in precipitation risk was found, depending on the positive/negative phases of the three atmospheric circulation patterns. Different phases of the circulation indices show contrasting effects on the two analyzed parameters. Thus, the most extreme daily precipitation during winter months is expected for negative WeMO events, representing a markedly different result to those obtained for 
other events. In contrast, negative NAO events record the most extreme precipitation magnitude risk per event, although this is mainly restricted to mountainous areas.

Key-words: Extreme precipitation, atmospheric circulation, Generalized Pareto distribution, return period, North Atlantic Oscillation, Western Mediterranean Oscillation, Mediterranean Oscillation, Northeast Spain.

\section{Introduction}

Atmospheric circulation dynamics is currently a priority research focus in atmospheric sciences, as it has implications for understanding climate variability and change. It is difficult to analyze and summarize variability in pressure fields because different phenomena overlap at different spatial scales. It is therefore necessary to reduce the degree of complexity via, for example, classification procedures [e.g., classification of daily weather types; Jones et al., 1993; Yarnal et al., 2001] and atmospheric circulation indices [e.g., Jones et al., 1997; Hurrell, 1995], thereby enabling a summary of the main atmospheric-pressure configurations that affect climate over large areas [Wallace and Gutzler, 1981; Trigo and Palutikof, 2001].

In the Northern Hemisphere, the main circulation pattern is the North Atlantic Oscillation (NAO), characterized by a north-south dipole structure with simultaneous atmospheric pressure anomalies between temperate and high latitudes in the North Atlantic region [Hurrell et al., 2003]. The surface climate of the Mediterranean region is also linked to other atmospheric configurations, such as the Mediterranean Oscillation, the Western Mediterranean Oscillation, and the East Atlantic/West Russian pattern [Krichak et al., 2002; Rodríguez-Puebla et al., 2001; Martín-Vide and López-Bustins, 2006; Dünkeloh and Jacobeit, 2003; Brunetti et al., 2002].

Atmospheric circulation explains most of the spatial and temporal variability in precipitation from global and hemispheric to regional scales. Dry and humid periods are 
commonly explained by anomalies in atmospheric pressure conditions, which persist from days to several months or even years. For example, the drought period that affected large areas of the Mediterranean region during the 1980s and 1990s was associated with positive phases of the NAO [Hurrell, 1995; Hurrell and van Loon, 1997]; however, there exist clear spatial differences in the influence of atmospheric circulation patterns on precipitation in the Mediterranean region [López-Moreno and Vicente-Serrano, 2008; González-Hidalgo et al., 2008], even across distances as small as $100 \mathrm{~km}$, mainly as a consequence of patterns of relief and the distribution of the seas and oceans [e.g., Goodess and Jones, 2002; Brunetti et al., 2002; Krichak et al., 2002]. The Iberian Peninsula represents the most extreme case of such spatial variability in precipitation within Europe. Located between the Atlantic Ocean and Mediterranean Sea, with a rugged topography, the peninsula shows marked spatial variability in the influence of atmospheric circulation on precipitation [e.g., Rodríguez-Puebla et al., 2001; Rodó et al., 1997; Vicente-Serrano and López-Moreno, 2006; Martín-Vide and López-Bustins, 2006; González-Hidalgo et al., 2008].

The majority of studies in this regard have been conducted at monthly or seasonal time scales. Obviously, medium and long time scales are of great interest for scientific research and the practical application of research findings related to the spatial and temporal variability of water-resources availability at different spatial scales [e.g., López-Moreno et al., 2007; Van der Schrier et al. 2006; López-Moreno and VicenteSerrano, 2007, 2008]; however, other processes, particularly those related to precipitation-related hazards, are commonly analyzed at shorter time scales [e.g., hourly: Kanae et al., 2004; Kao and Govindaraju, 2007; daily: Beguería and VicenteSerrano, 2006; Khan et al., 2007; Kysely and Picek, 2007; event-based scale: Beguería 
et al., 2008], as torrential flooding typically results from brief but intense rainfall [White et al., 1997; Barredo, 2007].

The relationship between atmospheric circulation and extreme precipitation upon the Iberian Peninsula has been studied previously based on weather type and atmospheric circulation indices. Previous attempts at relating the atmospheric circulation conditions and extreme precipitation events have commonly employed descriptive approaches that involve the identification of synoptic types for days in which high-precipitation events were recorded [e.g., Phillips and McGregor, 2001; Kahana et al., 2002; Peñarrocha et al., 2002; Twardosz and Niedzwiedz, 2001]. Such approaches reveal those atmospheric circulation types more likely to cause heavy precipitation, but they cannot provide a quantitative evaluation of extreme precipitation hazard to be applied in short-term meteorological predictions.

Other studies have analyzed the occurrence of heavy precipitation events from monthly or seasonal atmospheric configurations [Goodess and Jones, 2002; Gershunov and Cayan, 2003; Katz et al., 2003; Santos et al., 2005; Higgins et al., 2007; Scaife et al., 2008]. Most such studies have reported differences in the frequency distribution of daily precipitation series as a function of whether the month or season occurred within either a positive or negative phase of the relevant atmospheric circulation pattern. For example, Gallego et al. [2005] documented that the effect of NAO on precipitation is mainly recorded in the category of intense rainfall, both in terms of frequency and accumulated values, whereas light and moderate rainfall are less strongly affected. Haylock and Goodess [2004] and Rodrigo and Trigo [2007] related a decrease in the frequency of daily precipitation amounts (in South Europe) above the $90^{\text {th }}$ percentile to NAO trends over the years 1958-2000. Similar results were reported by Santos et al. [2007] using coupled models and scenarios. 
Previous approaches, although useful, do not enable an assessment of the relationship between individual heavy precipitation events and a specific atmospheric pressure configuration, or to determine the risk of occurrence of a precipitation event of given intensity in relation to the occurrence of a specific circulation pattern. Atmospheric pressure configurations that characterize circulation patterns commonly have durations of days or weeks [Feldstein, 2000; Jia et al., 2007]; therefore, the calculation of atmospheric circulation indices at daily time scales seems to be more appropriate than using monthly indices when determining the influence of atmospheric circulation on the risk of heavy precipitation. Previous studies have obtained daily indices of atmospheric circulation, demonstrating its reliability and practical use [Lin and Derome, 1999; Thompson and Wallace, 2001; Blessing et al., 2005; Martín-Vide and López-Bustins, 2006; Martín-Vide et al., 2008]. Such an approach enables the identification of individual atmospheric circulation events based on consecutive days that record the persistence of a given configuration of atmospheric pressure at sea level (SLP) [Jia et al., 2007], from which it is possible to analyze the associated risk of intense precipitation.

Although several studies have established the risk of extreme precipitation events in time and space [Prudhome and Reed, 1999; García-Ruiz et al., 2000; Casas et al., 2007; Beguería and Vicente-Serrano, 2006], no previous study has related the precipitation risk to individual atmospheric circulation events based on daily indices.

In the present paper, we analyze the probability of extreme precipitation in relation to different atmospheric circulation patterns. We develop a new methodological approach that includes daily classification of positive and negative phases of atmospheric circulation patterns, stochastic calculations based on parametric probability distributions, and spatial modeling based on GIS and regression-based interpolation. 
The method is applied to Northeast Spain, a region strongly affected by extreme precipitation events that cause frequent floods with a human and economic cost [White et al., 1997; Peñarrocha et al., 2002; Llasat and Rodríguez, 1992; Llasat et al., 2003].

\section{Methods}

\subsection{Daily precipitation database}

We employed a dense database of 174 complete series of daily precipitation amounts with continuous data between 1950 and 2006 (see Figure 1 for station locations). Data on cumulative precipitation were taken every day at 06:00 AM. The series were obtained via a process that included reconstruction, gap filling, quality control, and homogeneity testing [for details, see Beguería et al., 2008b].

\subsection{Definition of atmospheric circulation events}

In this study, atmospheric circulation indices were calculated from the differences between time series of SLP recorded at two points [Hurrell, 1995; Jones et al., 1997]. The influence of the following daily indices of atmospheric circulation (i.e., the three indices selected for analysis in the present study) on the precipitation of Northeast Spain has been recognized in previous studies: NAO, Mediterranean Oscillation (MO) [Conte et al., 1989; Palutikof, 2003], and Western Mediterranean Oscillation (WeMO) [MartínVide and López-Bustins, 2006]. The three patterns are mainly active during the boreal winter, when they determine the climate over extensive areas of Europe [Wanner et al., 2001; Martín-Vide and López-Bustins, 2006]. Accordingly, in the present study we used winter data (October-March).

The NAO index is commonly calculated from the gradient in surface pressure between observatories located in Iceland and the area west of the Iberian Peninsula, including the Azores. We used the approach described by Jones et al. [1997], based on the difference 
between the standardized surface pressures of the southwest Iberian Peninsula and southwest Iceland.

The MO summarizes the gradient in SLP anomalies between eastern and western areas of the Mediterranean Basin. This index was initially developed by Conte et al. [1989] as the difference in standardized geopotential height anomalies at Algiers (Algeria) and Cairo (Egypt). Palutikof [2003] extended the calculation to the extremes of the basin by considering the SLP anomalies between Gibraltar and Lod (Israel). We selected this latter approach for the present study to better record the influence over Northeast Spain. The WeMO index was defined by Martín-Vide and López-Bustins [2006] as a dipole structure that records the SLP anomaly gradient between the anticyclone over the Azores and the depression over Liguria (Italy). The authors calculated the WeMO index as the difference in standardized values of surface atmospheric pressure between San Fernando (Spain) and Padova (Italy). This index enables the detection of variability in precipitation related to cyclogenesis in areas adjacent to the western Mediterranean Basin, and is superior to other indices in explaining precipitation variability over large areas of the Spanish Mediterranean coast [González-Hidalgo et al., 2008].

To calculate the daily indices for winter (October-March), we used daily SLP grids from the ds010.0 Daily Northern Hemisphere Sea Level Pressure Grids dataset [UCAR/NCAR/CISL/DSS, 1979], which contains complete records over the present study period (1950-2006) with a spatial coverage of $5^{\circ} \times 5^{\circ}$. In calculating the NAO, MO, and WeMO indices, we selected those grid points located closest to the weather stations indicated above (Figure 2). The NAO was calculated as the daily normalized difference between the SLP at the point $35^{\circ} \mathrm{N}, 5^{\circ} \mathrm{W}$ and that at the point $65^{\circ} \mathrm{N}, 20^{\circ} \mathrm{W}$. The MO was calculated as the daily normalized difference between the SLP at the point $35^{\circ} \mathrm{N}, 5^{\circ} \mathrm{W}$ and that at the point $30^{\circ} \mathrm{N}, 35^{\circ} \mathrm{E}$. The WeMO was calculated as the daily 
normalized difference between the SLP at the point $35^{\circ} \mathrm{N}, 5^{\circ} \mathrm{W}$ and that at the point $45^{\circ} \mathrm{N}, 10^{\circ} \mathrm{E}$. The three daily indices show a high temporal variability and no inter-index correlation. As an example, Figure 3 shows the temporal evolution of the daily NAO, WeMO, and MO indices between 1 October 2006 and 31 December 2006.

The quality of the obtained daily atmospheric circulation indices were assessed by comparison with standard indices obtained at monthly time scales from station-derived pressure series. The Gibraltar-Reykjavik October-March NAO index was obtained from the monthly index NAO by Jones et al. [1997] (http://www.cru.uea.ac.uk/cru/data/nao.htm). The October-March MO index was obtained from a monthly MO index compiled by the Lod and Gibraltar observatories (http://www.cru.uea.ac.uk/ andrewh/moi.html). Finally, the monthly WeMO index calculated from surface atmospheric pressure in San Fernando (Spain) and Padua (Italy) was obtained from the Climatology Group, University of Barcelona (http://www.ub.es/gc/English/wemo.htm).

Figure 4 shows the evolution of October-March indices calculated from monthly SLP observations recorded at weather stations and the daily indices obtained from NCEP/NCAR SLP grids at the points located closest to the stations. The values differ between the daily and monthly indices because of the employed averaging calculations; however, the interannual variability is nearly identical between the two indices. The correlation coefficient between the daily- and monthly-based NAO indices is $\mathrm{R}=0.94$; the equivalent values for the WeMO and MO indices are $\mathrm{R}=0.88$ and $\mathrm{R}=0.90$, respectively.

The negative and positive phases of atmospheric circulation are not isolated phenomena of short duration: they tend to persist for between 5 and 21 days [Feldstein, 2000], making it possible to consider the occurrence of independent atmospheric circulation 
events for which the recorded precipitation can be ascribed to the corresponding circulation phase. We defined positive and negative events of the three atmospheric circulation indices following a similar method to that of Lin and Derome [1999] and Jia et al. [2007] in their study of the Pacific North American (PNA) and NAO patterns, respectively. Events were identified in the case that the atmospheric indices exceeded (were less than) $0.5(-0.5)$ of the standard deviation of the index for at least 8 consecutive days.

\subsection{Probabilistic analysis}

For each positive and negative NAO, WeMO, and MO event between 1950 and 2006, we obtained the total precipitation (magnitude) and the maximum daily precipitation (intensity, defined as the maximum daily precipitation recorded during the atmospheric circulation event) as recorded by each precipitation observatory. We selected the maximum daily precipitation to avoid a common problem encountered when analyzing precipitation series: the likely presence of serial dependence or persistence in the point process that arises because rainfall events tend to occur clustered in groups. This problem is especially acute for Mediterranean climates, for which long periods without rainfall are commonly followed by events that last for several days [Llasat and Puigcerver, 1997]. Such a rainfall pattern represents a major problem, as persistence is inconsistent with the premise of a homogeneous random process [Beguería, 2005]. We also analyzed the total precipitation during each atmospheric circulation event because of its significant implications for hazards: consecutive rainy days may lead to soil saturation, triggering regional floods and other natural hazards such as landslides [Gallart and Clotet-Perarnau, 1988; García-Ruiz et al., 2002].

The precipitation risk related to the three atmospheric circulation patterns was analyzed using the extreme value theory [Hershfield, 1973]. In this approach, the first task is to 
determine the most suitable function among the numerous existing distributions [Rao and Hamed, 2000] to model the magnitude and maximum intensity corresponding to positive and negative phases of the atmospheric circulation patterns. Following Ben-Zvi and Azmon [1997], the selection of a probability distribution for annual maximum discharges was carried out throughout explanatory and confirmatory stages. On the one hand, visual inspection of the L-moment ratio diagrams was used to select the most appropriate candidate distribution. Only the events for which there was precipitation (i.e., $\mathrm{x}>0 \mathrm{~mm}$ ) were included in the analysis to avoid problems with some distributions that not allow variables having a point mass at the origin. Details of calculation of Lmoments and L-moment ratios can be found in Rao and Hamed [2000], and details of the L-moment ratio diagrams in Hosking [1990]. On the other hand, the goodness of fit between the sample and the reference probability distribution was checked by means of the nonparametric Kolmogorov-Smirnov (KS) test at critical level $\alpha=0.05$. The KS test is based on the KS distance statistic, which quantifies the maximum vertical distance between the empirical distribution function (ECDF) of the sample and the cumulative distribution function (CDF) of the reference distribution. In this case, the ECDF was calculated using the plotting position formula proposed by Hosking [1990] for highly skewed data:

$$
P(X \leq x)=\frac{i-0.35}{N}
$$

where $i$ is the rank of the observations arranged in increased order, and $N$ is the number of observations. CDF was calculated using the formula on equation (5) and the parameters estimated from the samples. The KS test checks the null hypothesis that the sample is drawn from the reference distribution (the GP distribution in this case). Besides, probability-probability (P-P) plots were produced for all the series to visually confirm the fit of the data to the GP distribution. P-P plots are constructed by plotting 
the CDF vs the ECDF corresponding to the observations. The closest the curve drawn by these points is to the 1:1 diagonal line, the better is the agreement between both distribution functions.

Figures 5 to 7 show the L-moment diagrams for $\tau_{3}$ and $\tau_{4}$ corresponding to the magnitude and maximum intensity precipitation series obtained from the positive and negative phases of the NAO, WeMO, and MO. Independently of the atmospheric circulation pattern and the sign of the event, the empirical L-moments of the precipitation series plotted close to the theoretical curve of the Generalized Pareto (GP) distribution. The results of the Kolmogorov-Smirnov test allowed accepting the GP distribution for the data, since only in very few cases the null hypothesis that the data came from a GP distribution was rejected (Figure 8). In most cases, the p-value of the KS distance statistic was well above 0.25 . This result agrees with recent studies that demonstrated the high performance of the GP distribution in fitting extreme hydrological variables using partial duration series [Madsen and Rosbjerg, 1997; Beguería, 2005; Hosking and Wallis, 1987]. Here we also found that the GP distribution has a good performance in fitting the precipitation data clustered according to the occurrence of different atmospheric circulation events.

It is well known that the GP distribution is the limit distribution of peaks-over-threshold (POT) series, provided that the exceedance occurrences behave like a Poisson process, i.e. they are time-independent. In this case, the sampling of the precipitation series was forced by the occurrence of an external event determined by an atmospheric circulation index. We checked whether the point process defined by the indices fit a Poisson process, so the events can be considered time-independent. Values of the dispersion index ( $D I$, ratio between the variance and the average occurrences per year) of the event series defined by several synoptic indices were calculated. If the point process follows a 
Poisson distribution, the value of the $D I$ statistic must be approximately 1 . Confidence limits for the $D I$ statistic can be constructed from a chi ${ }^{2}$ distribution at $n-1$ degrees of freedom, $n$ being the number of years of the series [Cunnane, 1979]. In this case, the upper and lower confidence limits at a significance level $\alpha=0.05$ were 1.411 and 0.6590, respectively. The null hypothesis that the point process follows a Poisson distribution was only rejected for the MO+ events (Table 1).

From the POT perspective, only the events for which there was precipitation were considered, so a threshold value of $0 \mathrm{~mm}$ was implicit on the data. We checked the convenience of the GP distribution by means of the mean residual life plot [MRL; Coles, 2001]. The MRL plot shows the mean exceedance as the threshold value increases, and it should be approximately linear for a GP distribution (up to a certain value over which there are few observations and the statistic becomes very unstable). In most cases, it was found that the assumption of a constant MRL was validated by the plots, as it can be seen in Figure 9 for maximum intensity series in five selected observatories. For magnitude series the results were similar (not shown). Therefore, we consider that this, together with the other tests, proof the convenience of using the GP distribution.

The GP distribution is described by a shape parameter $\kappa$ and a scale parameter $\alpha$, with the following probability density function:

$$
f(x)=\frac{1}{\alpha}\left[1-\frac{k}{\alpha}(x-\varepsilon)\right]^{1 / k-1},
$$

where $x$ is the magnitude or maximum intensity of an event exceeding $0 \mathrm{~mm}$ and $\varepsilon$ is a location parameter or distribution origin that corresponds to the lowest value of the series of $x$. The parameters of the distribution are easily estimated from the L-moments of the data series [Hosking, 1990]: 
$\alpha=\lambda_{1}\left(\frac{1}{\tau}-1\right)$

$\kappa=\frac{1}{\tau}-2$

where $\lambda_{1}, \lambda_{2}$ are the first two probability-weighted moments and $\tau=\lambda_{2} / \lambda_{1}$.

The CDF of the GP distribution is obtained as:

$P(X \leq x)=1-\left(1-\kappa \cdot \frac{(x-\varepsilon)}{\alpha}\right)^{\frac{1}{\kappa}}$

The probability that an event of magnitude or intensity greater than zero is also greater than a value $x$ can be calculated simply as $1-P(X \leq x)$.

The former equations apply only to events for which the precipitation (magnitude or intensity) was higher than zero. However, atmospheric circulation events for which no precipitation was observed were frequent in the data, so the probability of not having precipitation was actually higher than zero. A correction can be made to the model outlined by equation 5 to take into account the probability of having zero precipitation, by expressing the exceedance probability, $P(X>x)$, in the form of the return period. The maximum expected precipitation magnitude or intensity $X_{T}$ over a period of $T$ years is obtained as follows:

$$
X_{T}=\varepsilon+\frac{\alpha}{\kappa}\left[1-\left(\frac{1}{\lambda T}\right)^{\kappa}\right] \text {, }
$$

where $\lambda$ (not to be missed with the probability weighted moments, $\lambda_{1}$ and $\lambda_{2}$ ) is the average annual number of events for which $\mathrm{x}>0$, given a positive or negative atmospheric circulation event.

\subsection{Spatial modeling}


In terms of mapping areas of extreme precipitation risk, Casas et al. [2007] and Beguería and Vicente-Serrano [2006] demonstrated the large improvement gained by employing technologies based on GIS and regression-based modeling. Therefore, to obtain an accurate spatial distribution of the precipitation risk associated with the three atmospheric circulation patterns considered in the present study, we followed the approach developed by Beguería and Vicente-Serrano [2006] based on regional extreme value analysis to obtain a single, common model of the probability of extreme events. This method yields smooth, continuous spatial representations of the probability distribution parameters, resulting in coherent and robust regional models and simplifying spatial estimates of the extreme quantiles [Beguería and Vicente-Serrano, 2006]. Moreover, the technique not only enables the use of information contained in the data series, but also the relationships between the modeled variable and other geographic parameters such as relief or location with respect to the main climatic drivers.

During the past decade, several alternative forms of combined global and local models have been proposed for interpolating spatially explicit environmental variables; e.g., different combinations of kriging and regression [Ninyerola et al., 2007; Brown and Comrie, 2002; McBratney et al., 2003; Vicente-Serrano et al., 2007]. These and other studies have demonstrated that combined models usually allow for more precise and detailed representations of the target variables. In our case, GP parameter estimates $(\varepsilon$, $\alpha, \kappa)$ and $\lambda$ at ungauged locations were obtained via the following equation:

$$
z(x)=b_{0}+b_{1} P_{1}+b_{2} P_{2}+\ldots+b_{n} P_{n}
$$

where $z$ is the predicted value of the GP parameter at point $x, b_{0} \ldots b_{n}$ are the regression coefficients, and $\mathrm{P}_{1} \ldots \mathrm{P}_{\mathrm{n}}$ are the values of the different independent variables at point $x$. 
For this purpose, we used a set of independent variables as covariates at a spatial resolution of $1000 \mathrm{~m}$ (Table 2). Elevation is usually the main determinant of the spatial distribution of climatic variables, although other factors such as latitude, longitude, distance to the ocean, slope gradient and aspect, and incoming solar radiation may also play an important role. The slope aspect may be important in modeling peak intensity, magnitude, and duration parameters, because it accounts for the effect of wind flow on precipitation events. Incoming solar radiation is a spatially continuous variable associated with terrain aspect (northern and southern slopes have low and high values of incoming solar radiation, respectively). Digital coverage of annual mean incoming solar radiation was created using MiraMon GIS and a Digital Elevation Model (DEM) according to Pons and Ninyerola [2008]. Low-pass filters with radii of 5, 10, and $25 \mathrm{~km}$ were applied to elevation, slope, and incoming solar radiation models to measure the wider influence of these variables. Such a large number of independent variables gives rise to the problem of co-linearity (i.e., correlations among independent variables), which causes computational instability and invalidates the results of regression analysis. To address this problem, we used a forward stepwise procedure with a restrictive 'probability to enter' ( $\alpha=0.01$ ) to select only significant variables, as recommended by Hair et al. [1998].

Given that regression-based methods are inexact because the predicted value of the variable $z(x)$ does not coincide with data collected at weather stations, we applied a performed correction based on the residual (difference between the parameter measured at the precipitation observatory and that predicted by the model), which is commonly interpolated over the entire territory using local techniques. This procedure has been used previously by Ninyerola et al. [2007], Agnew and Palutikof [2000], Brown and Comrie [2002], and Beguería and Vicente-Serrano [2006], among others. In the present 
paper, we used a method of splines with tension [Mitasova and Mitas, 1993], yielding a set of maps of the spatial estimates of the parameters of the GP distribution $(\varepsilon, \alpha, \kappa)$ and of the annual frequency of events $(\lambda)$ for the magnitude and daily maximum intensity precipitation series corresponding to the positive and negative events of the NAO, WeMO, and MO circulation patterns. The probability of the occurrence of a precipitation event with maximum intensity above $50 \mathrm{~mm}$ and an event with magnitude above $100 \mathrm{~mm}$ were calculated directly from the parameter maps over a period of 50 years, as were the quantile estimates.

\section{Results}

\subsection{Frequency of occurrence of circulation events}

Figure 10 shows a duration boxplot of positive $(+)$ and negative $(-)$ events of the three atmospheric circulation indices. The criterion employed in selecting atmospheric circulation events means that the minimum duration is always 8 days for the positive and negative events. There is a high frequency of long-duration events for $\mathrm{NAO}+$, NAO-, and WeMO- events. The WeMO+ events show the shortest average duration (9 days) and a low frequency of long-duration events. WeMO+ events are the least frequent (100 wintertime events recorded between 1950 and 2006), whereas NAOevents are the most frequent (232 events). NAO+, $\mathrm{MO}-$, and $\mathrm{MO}+$ events were recorded 160, 102, and 123 times, respectively. The WeMO- events were also widely recorded between 1950 and 2006 (156 events, with a maximum duration of 121 days).

\subsection{At-site evaluation}

Figure 11 shows the values of maximum daily precipitation and precipitation magnitude for the different centiles corresponding to the positive and negative NAO, WeMO and MO events for five representative precipitation observatories. For the NAO the majority 
of the precipitation observatories, mainly in the Mediterranean area (Castellón and Barcelona), the magnitude and the daily maximum intensity are higher from the $40^{\text {th }}$ to $100^{\text {th }}$ centiles for negative events than for positive events. The inland observatories (Monzón de Campos and Zaragoza) and the northern observatory (Articutza) show smaller differences between the positive and negative NAO events. Compared with NAO events, the WeMO events show larger differences between observatories and between positive and negative phases. Inland observatories (Zaragoza and Monzón de Campos) show no noticeable differences between WeMO+ and WeMO- events, whereas clear differences are recorded at Mediterranean coastal observatories (Castellón and Barcelona) for both precipitation magnitude and the maximum daily intensity series. The highest precipitation values are obtained for WeMO- events, and the difference between WeMO+ and WeMO- events is more pronounced for the highest centiles. Thus, a precipitation close to $0 \mathrm{~mm}$ could be expected for $\mathrm{WeMO}+$ events (64\% of WeMO+ events recorded at the Castellón observatory show a magnitude and intensity of $0 \mathrm{~mm}$ ). The opposite pattern is found for the Articutza observatory (northeast part of the Basque country), with contrasting precipitation frequencies between WeMO+ and WeMO- events. Values of the maximum daily precipitation and magnitude are very high for positive events, with maximum recorded values of 217 and $510.1 \mathrm{~mm}$, respectively. For the MO the Mediterranean coastal observatories (Barcelona and Castellón) show similar patterns to those observed for WeMO events, with a higher precipitation magnitude and maximum daily intensity for negative events than for positive events. The same behavior is observed for the inland observatories (Zaragoza and Monzón de Campos), although with greater differences between positive and negative events compared with NAO and WeMO events. The Articutza observatory (in the north of the study area) also records a higher magnitude and maximum intensity of 
precipitation for positive (MO) events than for negative events, as observed for WeMO. Nevertheless, such differences are only identified for the upper centiles, and the magnitude of the differences is much lower than that found for WeMO.

Figure 12 shows probability-probability (P-P) plots for the same five stations for the precipitation intensity series. P-P plots show the probabilities modeled by the Generalized Pareto distribution against the empirical probabilities calculated by equation (1). The closest the curve is to the central 1:1 line, the better is the fitting between the empirical distribution and the model. The results indicate a very good agreement between the empirical and the GP modeled probabilities. Similar P-P plots were obtained for the rest of the series, as well as for the precipitation magnitude (results not shown).

3.3. Spatial models of the precipitation risk associated with atmospheric circulation events

Figure 13 shows, as an example, the spatial distribution of the GP $\alpha$ parameter corresponding to the maximum intensity series for NAO- events, and the $\lambda$ statistic of the magnitude series for WeMO+ events. These maps show the high capability in using regression-based modeling to obtain a reliable spatial estimation of the GP parameters, in which the spatial distribution is not solely determined by the location of the precipitation observatories.

Figure 14 shows, as an example, the non-exceedance probability curves for maximum daily precipitation intensity and positive and negative NAO, WeMO, and MO events for three representative observatories (Zaragoza, Barcelona and Articutza). For both Zaragoza and Barcelona, the occurrence probability of high-precipitation events is higher for negative events, regardless of atmospheric circulation pattern. At Zaragoza, the probability is higher for WeMO- events, for which the probability of a precipitation 
event $>50 \mathrm{~mm}$ is $9 \%$. For positive events of the three circulation patterns and MOevents, the probability of maximum daily precipitation $>50 \mathrm{~mm}$ is very low. The probability curves calculated for the Barcelona observatory are markedly different from those calculated for the Zaragoza observatory. For positive events of all three atmospheric circulation patterns, the curves show the same behavior, with very low probability of maximum daily precipitation $>50 \mathrm{~mm}$. The probability of maximum daily precipitation $>50 \mathrm{~mm}$ is higher for $\mathrm{MO}-$ events $(13.3 \%)$ than for NAO- events (4.8\%), but the highest probabilities are recorded for WeMO- events, for which the probability of maximum daily precipitation $>50 \mathrm{~mm}$ is very high (22.1\%). In Articutza the pattern is the opposite, in which the positive phases show a higher probability of a very intense daily precipitation than the negative phases. For example, in the WeMO+ and $\mathrm{MO}+$ events the probability of maximum daily precipitation $>50 \mathrm{~mm}$ is very high (36.5\% and 23.2\%, respectively)

Figure 15 shows the spatial distribution of the probability of maximum daily precipitation $>50 \mathrm{~mm}$ and total precipitation magnitude $>100 \mathrm{~mm}$ during positive and negative NAO, WeMO, and MO events. The probability of maximum daily precipitation $>50 \mathrm{~mm}$ shows different spatial patterns as a function of the sign of the event, and clear differences are found between the three atmospheric circulation patterns. The probability is very low throughout the entire study area for $\mathrm{NAO}+$ events. The probability is higher for NAO- events, mainly in the north and northeast of the study area. Values range between the $15 \%$ in northeast Catalonia and $25 \%$ in parts of the central Pyrenees. WeMO+ events show a high probability of maximum daily precipitation $>50 \mathrm{~mm}$ along the northern Atlantic coast (15-35\%), but a probability close to $0 \%$ in other areas. In contrast, WeMO- phases show a high probability of maximum daily precipitation $>50 \mathrm{~mm}$, mainly in Mediterranean coastal areas and the 
Eastern Pyrenees (> 45\% in some areas). The southwest and northwest parts of the study area also show high probability values (15-28\%), maybe related to the reinforcement of the role of the southeasterly flows associated to $\mathrm{WeMO}+$ events as a consequence of relief configuration. For $\mathrm{MO}+$ events, the probability of maximum daily precipitation $>50 \mathrm{~mm}$ is very low; only in the northwest are values in the range $5-15 \%$. Nevertheless, for MO- events the probability of maximum daily precipitation $>50 \mathrm{~mm}$ is very high in the mountainous areas in the north and northeast, and in coastal and inland areas of eastern Catalonia (probabilities exceed 40\% in places). The remainder of Mediterranean coastal areas record lower probabilities (5-12\%), although high relative to those for $\mathrm{MO}+$ events.

Figure 15 also shows the probability of total precipitation magnitude $>100 \mathrm{~mm}$ during each event. Several marked differences are observed compared with maximum daily precipitation results. WeMO- events show a low probability of precipitation magnitude $>100 \mathrm{~mm}$, indicating that precipitation during WeMO- events is potentially intense but not sustained throughout the entire event, especially for Mediterranean coastal areas. The opposite pattern is observed for northern areas, for which WeMO+ events are associated with a high probability of precipitation magnitude $>100 \mathrm{~mm}$ (large areas show values $>50 \%$ ). This finding indicates that although WeMO+ events are not associated with an intense precipitation risk in North Spain, they are related to a high precipitation amount during the entire event.

$\mathrm{NAO}+$ and NAO- events show a similar spatial pattern to that found for the probability of maximum daily precipitation intensity, with the probability of precipitation magnitude $>100 \mathrm{~mm}$ being below $15 \%$ for the entire study area, with the exception of some sectors in the central Spanish Pyrenees and the northwest. Nevertheless, this probability is high for MO- events, mainly in Pyrenean areas (probabilities $>45 \%$ ) but 
also in Mediterranean coastal areas (> 25\%) and some mountainous areas of the Iberian (> 28\%) and Cantabrian ranges (> 35\%).

Figure 16 shows quantile maps of maximum daily intensity and total magnitude of precipitation corresponding to NAO, WeMO, and MO events with a return period of 50 years. The most intense maximum daily precipitation events are associated with negative phases of the WeMO, with values above $350 \mathrm{~mm}$ in some areas of Northeast Catalonia and values of $250-330 \mathrm{~mm}$ in northern coastal areas. In other areas, high precipitation intensities are expected to be associated with these events: $63.3 \%$ of the study area shows a maximum daily precipitation for WeMO- events of $>80 \mathrm{~mm}$ for a period of 50 years. For MO- events, although Figure 15 showed a high probability of maximum daily precipitation $>50 \mathrm{~mm}$ across large areas of the Pyrenees and northeastern Catalonia, the maximum expected maximum daily precipitation over a 50year interval is much lower than that observed for WeMO- events, with maximum daily values of around $145 \mathrm{~mm}$ in parts of the Catalan Pyrenees. We found similar values (around $150 \mathrm{~mm}$ over a 50-year period) for NAO- events in the central and eastern Pyrenees. For positive events of all three atmospheric circulation patterns, the maximum daily precipitation is below $60 \mathrm{~mm}$ for the majority of the study area; only in northern coastal areas is the expected maximum daily precipitation higher than $70 \mathrm{~mm}$ during positive WeMO and MO events (the maximum obtained value is $115 \mathrm{~mm}$ around the Articutza observatory for WeMO+ events).

Regarding maximum precipitation magnitude for a return period of 50 years, high values are expected for NAO- phases in the Pyrenees, northern Atlantic coastal areas, and Mediterranean coastal areas (> $440 \mathrm{~mm}$ in some sectors of the central Spanish Pyrenees). For NAO+ phases, precipitation magnitudes above $200 \mathrm{~mm}$ are only expected for northwest parts of the Atlantic coastal area. In contrast, for positive WeMO 
and MO events, large areas close to the Atlantic coast show a precipitation magnitude above $300 \mathrm{~mm}$ for a unique event, whereas the majority of the study area shows very low precipitation magnitudes associated with these events. For WeMO- events, we found only minor differences among atmospheric circulation events compared with those identified for maximum daily precipitation intensity. Although high-magnitude precipitation is expected for some areas of the Catalan Pyrenees and Mediterranean coastal areas (> $400 \mathrm{~mm}$ ), the pattern is similar to that obtained for NAO- events; a similar spatial pattern is observed for MO- events, although the maximum magnitude expected over a period of 50 years is lower than that for NAO- and WeMO- events.

\section{Discussion and conclusions}

In this paper, we reported the precipitation risk for the northwest Iberian Peninsula associated with positive and negative events of three different atmospheric circulation patterns (NAO, MO, and WeMO). The analysis was conducted at a daily time scale, as required to accurately quantify the precipitation-related risks. The obtained results reveal that the most extreme daily precipitation in winter months is expected for WeMO- events, with large differences observed among other events. In contrast, NAOevents record the highest risk of the most extreme precipitation magnitude per event, although mainly restricted to mountainous areas.

To enable an evaluation of the risk of heavy precipitation associated with various atmospheric circulation types, some studies have followed a probabilistic approach [Kiely et al., 1998; Katz et al., 2003; Gallego et al., 2005] in determining differences in the frequency distribution of daily precipitation as a function of months or seasons with a dominant atmospheric circulation pattern. Although this approach may provide insight into high or low precipitation risks associated with certain synoptic conditions, it is not 
possible to directly associate precipitation risk with a given atmospheric circulation pattern.

An event-based approach enables the user to determine the actual risk of extreme precipitation associated with each atmospheric circulation pattern. In the present paper, we quantitatively determined the probability of heavy precipitation associated with different atmospheric circulation patterns, with direct implications for short-term meteorological predictions and hazard management.

We have shown that the precipitation intensity and magnitude corresponding to events defined by atmospheric circulation events fit a Poisson process, so the events can be considered time-independent. Besides, we have found that the Generalised Pareto distribution could be used to model the series of the events for which there was precipitation. This is in agreement with recent studies using exceedance series above a high threshold [Beguería, 2005; Hosking and Wallis, 1987]. Here we have also demonstrated that the GP distribution also shows the best performance in fitting the precipitation data clustered according to the occurrence of different atmospheric circulation events.

The use of regression-based interpolation assisted by GIS and digital terrain layers has enabled us to overcome common problems related to the low spatial density of observatories and to obtain accurate estimates for areas in which such observations are commonly limited (e.g., mountainous areas) and for which high precipitation intensities are expected.

The maps of precipitation probability and quantiles presented in this paper demonstrate several spatial characteristics that are of great importance in understanding the spatial distribution of extreme precipitation risk in the region, yet which would not be possible to map if auxiliary data such as elevation and other terrain variables were not included 
in the GIS modeling. The combination of this method and atmospheric circulation event/precipitation probabilistic analysis is a powerful tool in improving the short-term forecasting of extreme precipitation, as the atmospheric circulation indices employed in the present study are easier to predict than precipitation over the short term.

Regarding spatial patterns of heavy precipitation risk related to the NAO, WeMO, and MO patterns, previous studies have reported the spatial pattern of influence of these atmospheric circulation patterns on the Iberian peninsula [e.g., González-Hidalgo et al., 2008; Rodríguez-Puebla et al., 2001; Martín-Vide and López-Bustins, 2006], although these studies were based on monthly data.

The results are geographically coherent in relation to the flows connected to the positive and negative phases of the three atmospheric circulation patterns. For example, the WeMO+/WeMO- maps show an explicit gradient NW-SE/SE-NW, which is related to the pluviometric effect of the associated northwesterly/southeasterly flows (Martín-Vide et al., 2008).

Moreover, the event-based approach employed in the present study enables the identification of a number of interesting patterns that were not identified in previous studies. For example, the spatial pattern of risk of extreme precipitation associated with NAO- events are commonly associated with southwest flows that cross the Iberian Peninsula from the southwest to the northeast as a consequence of the presence of a low pressure centre to the northwest of the Iberian Peninsula. This pattern has a strong effect on precipitation variability in the southwest of the peninsula [e.g., Rodó et al., 1997]. The southwesterly flows associated to NAO- events, however, decrease in intensity when crossing the peninsula, being relatively devoid of moisture by the time they reach northeast Spain This pattern has a strong effect on precipitation variability in the southwest of the peninsula [e.g., Rodó et al., 1997]; however, the southwesterly flows, 
associated to NAO- events, decreases in intensity when crossing the peninsula, being relatively devoid of moisture by the time it reaches northeast Spain. This explains why heavy daily precipitation is not expected during these events but high precipitation magnitudes are predicted in mountainous areas, as the southwesterly flows are reactivated in the Pyrenees [Esteban et al., 2002], some sectors of the Iberian range, and the coastal Catalan chains due to the effects of relief. For NAO+ events, the maps show very low intensity and magnitude of precipitation as a consequence of the dominant dry northeastern flows associated to a high pressure center located northwest of the Iberian Peninsula. Only a high probability of heavy precipitation magnitude was found for $\mathrm{NAO}+$ events in some sectors of the northernmost areas, which are open to northeastern flows as a consequence of the absence of East-West topographic barriers that characterize the rest of the study area.

The MO events show a low probability of high precipitation intensity, both for positive and negative phases over the entire study area. On the contrary, the precipitation amount during the events shows noticeable spatial differences, clearly related to the flows that characterize MO events: advections from the East and West for negative and positive phases, respectively. These advections are related to weather types that show a low pressure center in North Africa and a high pressure center over the British Islands, but also to weather types characterized by a low pressure center to the South of the Gulf of Lion, affecting the flows associated to the northernmost sectors of Catalonia and the central Pyrenees.

Martín-Vide and López-Bustins [2006] identified the different roles of the positive and negative WeMO phases, which result in high precipitation amounts in Atlantic and Mediterranean coastal areas, respectively. Nevertheless, our analysis of WeMO events based on daily precipitation revealed that precipitation associated with this atmospheric 
circulation pattern has strongly contrasting characteristics between the north (positive phases) and Mediterranean coastal areas (negative phases). Although a high precipitation amount is recorded in both areas in response to both signs of the atmospheric circulation pattern, Mediterranean coastal areas are associated with very high daily precipitation risk, whereas Atlantic coastal areas are associated with a high precipitation magnitude throughout the event itself. Despite the high intensity of precipitation in Mediterranean coastal areas, it tends to be concentrated in relatively few days [Martín-Vide, 2004]. In fact, extreme precipitation events are usually concentrated within a period of several hours, and have a marked spatial concentration because of the importance of local relief, which favors the formation of convective systems associated with the southeasterly flows that characterize WeMO- events. This finding explains the large differences recorded between maximum daily precipitation intensity and precipitation magnitude risk associated with WeMO- events.

The methodology presented in the current study enabled the detection of notable spatial heterogeneity in quantile estimates of maximum daily precipitation and magnitude of precipitation as a function of positive and negative phases of the three analyzed atmospheric circulation patterns. This finding demonstrates the usefulness of this methodology as a practical tool in estimating regional hazard risks, such as in planning preventative measures against regional torrential floods, or in land planning and management.

\section{Acknowledgements}

This work was supported by projects financed by the Spanish Commission of Science and Technology (CGL2005-04508/BOS and CGL2008-01189/BTE), the 7th framework programme of the European Commission (projects ACQWA and EUROGEOSS), and 
the "Programa de grupos de investigación consolidados" financed by the Aragón

Government.

\section{References}

Agnew MD, Palutikof JP. 2000. GIS-based construction of base line climatologies for the Mediterranean using terrain variables. Climate Research 14: 115-127.

Barredo JI. 2007. Major flood disasters in Europe: 1950-2005. Natural Hazards 42: 125-148.

Beguería S. 2005. Uncertainties in partial duration series modelling of extremes related to the choice of the threshold value. Journal of Hydrology 303: 215-230.

Begueria S, Vicente Serrano SM. 2006. Mapping the hazard of extreme rainfall by peaks-over-threshold extreme value analysis and spatial regression techniques. Journal of Applied Meteorology and Climatology 45: 108-124.

Beguería S, Vicente-Serrano SM, López-Moreno JI, García-Ruiz JM. 2008. Annual and seasonal mapping of peak intensity, magnitude and duration of extreme precipitation events across a climatic gradient, North-east Iberian Peninsula. International Journal of Climatology.

Beguería S, Vicente-Serrano SM, López-Moreno JI, García-Vera MA, Stepanek P. 2008b. A complete daily precipitation database for North-East Spain: reconstruction, quality control and homogeneity. International Journal of Climatology

Ben-Zvi A, Azmon B. 1997. Joint use of L-moment diagram and goodness-of-fit test: a case study of diverse series. Journal of Hydrology 198: 245-259.

Blessing S, Fraedrich K, Junge M, Kunz T, Lunkeit F. 2005. Daily North-Atlantic Oscillation (NAO) index: Statistics and its stratospheric polar vortex dependence Meteorologische Zeitschrift 14: 763-769.

Brown DP, Comrie AC. 2002. Spatial modeling of winter temperature and precipitation in Arizona and New Mexico, USA. Climate Research 22: 115-128.

Brunetti M, Maugeri M, Nanni T. 2002. Atmospheric circulation and precipitation in Italy for the last 50 years. International Journal of Climatology 22: 1455-1471.

Casas MC, Herrero M, Ninyerola M, Pons X, Rodríguez R, Rius A, Redaño A. 2007. Analysis and objective mapping of extreme daily rainfall in Catalonia. International Journal of Climatology 27: 399-409.

Coles S., 2001. An Introduction to Statistical Modeling of Extreme Values. SpringerVerlag, 208 pp.

Conte M, Giuffrida A, Tedesco S. 1989. The Mediterranean Oscillation. Impact on precipitation and hydrology in Italy Climate Water. Publications of the Academy of Finland, Helsinki.

Cunnane, C., 1979. A note on the Poisson assumption in partial duration series models. Water Resources Research 15: 489-494.

Dünkeloh A, Jacobeit J. 2003. Circulation dynamics of Mediterranean precipitation variability 1948-98. International Journal of Climatology 23: 1843-1866.

Esteban P, Soler X, Prohom M, Planchon O. 2002. La distribución de la precipitación a través del índice NAO. El efecto del relieve a escala local: El Pirineo Oriental. El Agua y el Clima, J. A. Guijarro et al., Eds., Asociación Española de Climatología, 25-34. 
Feldstein, S.B. 2000. The timescale, power spectra, and climate noise properties of teleconnection patterns. Journal of Climate 13: 4430-4440.

Gallart F, Clotet-Perarnau N. 1988. Some aspects of the geomorphic processes triggered by an extreme rainfall event: the November 1982 flood in the Eastern Pyrenees. Catena Suppl. 13: 79-95.

Gallego MC, García JA, Vaquero JM. 2005. The NAO signal in daily rainfall series over the Iberian Peninsula. Climate Research 29: 103-109.

García-Ruiz JM, Arnáez J, White SM, Lorente A, Beguería S. 2000. Uncertainty assessment in the prediction of extreme rainfall events: An example from the central Spanish Pyrenees. Hydrological Processes 14, 887-898.

García-Ruiz JM, Martí-Bono C, Lorente A, Beguería S. 2002. Geomorphological consequences of frequent and infrequent pluviometric and hydrological events in a Mediterranean mountain area. Mitigation and adaptation strategies for global change 7: 303-320.

Gershunov A, Cayan DR. 2003. Heavy daily precipitation frequency over the contiguous United States: Sources of climatic variability and seasonal predictability. Journal of Climate 16: 2752-2765

González-Hidalgo JC, López-Bustins JA, Štepánek P, Martín-Vide J, de Luis M. 2008. Monthly precipitation trends on the Mediterranean fringe of the Iberian Peninsula during the second half of the 20th century (1951-2000). International Journal of Climatology.

Goodess CM, Jones PD. 2002. Links between circulation and changes in the characteristics of Iberian rainfall. International Journal of Climatology 22: 1593-1615.

Hair JF, Anderson RE, Tatham RL, Black WC. 1998. Multivariate Data Analysis. Prentice Hall International, Inc.: New York; 799.

Haylock MR, Goodess CM. 2004. Interannual variability of European extreme winter rainfall and links with mean large-scale circulation. International Journal of Climatology 24: 759-776.

Hershfield DM. 1973. On the probability of extreme rainfall events. Bulletin of the American Meteorological Society 54: 1013-1018.

Higgins RW, Silva VBS, Shi W, Larson J. 2007. Relationships between climate variability and fluctuations in daily precipitation over the United States. Journal of Climate 20: 3561-3579.

Hosking JRM. 1990. L-moments: analysis and estimation of distributions using linear combinations of order statistics. Journal of the Royal Statistical Society Series B: Methodological 52: 105-124.

Hosking JRM, Wallis JR. 1987. Parameter and quantile estimation for the Generalized Pareto distribution. Technometrics 29: 339-349.

Hurrell J. 1995. Decadal trends in North Atlantic Oscillation and relationship to regional temperature and precipitation. Science 269: 676-679.

Hurrell J. van Loon H. 1997. Decadal variations in climate associated with the North Atlantic Oscillation. Climatic Change 36, 301-336.

Hurrell J, Kushnir Y, Ottersen G, Visbeck M. 2003. The North Atlantic Oscillation: Climate significance and environmental impacts. American Geophysical Union, Washington, USA.

Jia XJ, Derome J, Lin H. 2007. Comparison of the life cycles of the NAO using different definitions. Journal of Climate 20: 5992-6011. 
Jones PD, Hulme M, Briffa KR. 1993. A comparison of Lamb circulation types with an objective classification scheme. International Journal of Climatology 13: 655663.

Jones PD, Jónsson T, Wheeler D. 1997. Extension to the North Atlantic Oscillation using early instrumental pressure observations from Gibraltar and South-West Iceland. International Journal of Climatology 17: 1433-1450.

Kahana R, baruch Z, Yehouda E, Dayan U. 2002. Synoptic climatology of major floods in the Negev desert, Israel. International Journal of Climatology 22: 867-882.

Kanae S, Oki T, Kashida A. 2004. Changes in hourly heavy precipitation at Tokyo from 1890 to 1999. Journal of the Meteorological Society of Japan 82: 241-247.

Kao SC, Govindaraju, RS. 2007. A bivariate frequency analysis of extreme rainfall with implications for design. Journal of Geophysical Research D: Atmospheres 112. art. no. D13119.

Katz, R.W., Parlange, M.B., Tebaldi, C. 2003. Stochastic modeling of the effects of large-scale circulation on daily weather in the southeastern U.S. Climatic Change 60: 189-216.

Khan S, Kuhn G, Ganguly AR, Erickson III DJ, Ostrouchov G. 2007. Spatio-temporal variability of daily and weekly precipitation extremes in South America. Water Resources Research 43: art. no. W11424.

Kiely G, Albertson JD, Parlange MB, Katz RW. 1998. Conditioning stochastic properties of daily precipitation on indices of atmospheric circulation. Meteorological Applications 5: 75-87.

Krichak SO, Kishcha P, Alpert P. 2002. Decadal trends of main Eurasian oscillations and the eastern Mediterranean precipitation. Theoretical and Applied Climatology 72: 209-220.

Kysely J, Picek J. 2007. Probability estimates of heavy precipitation events in a floodprone central-European region with enhanced influence of Mediterranean cyclones. Advances in Geosciences 12: 43-50.

Lin H, Derome J. 1999. The genesis and predictability of persistent Pacific-North American anomalies in a model atmosphere. Tellus, Series A: Dynamic Meteorology and Oceanography 51: 686-697.

Llasat MC, Rodríguez R. 1992. Extreme rainfall events in Catalonia. The case of 12 November 1988. Natural Hazards, 5: 133-151.

Llasat MC, Puigcerver M. 1997. Total rainfall and convective rainfall in Catalonia, Spain. International Journal of Climatology 17: 1683-1695.

Llasat MD, Rigo T, Barriendos M. 2003. The 'Montserrat-2000' flash-flood event: A comparison with the floods that have occurred in the northeastern Iberian Peninsula since the 14th century. International Journal of Climatology 23: 453469.

Lopez-Moreno JI, Vicente-Serrano SM. 2007. Atmospheric circulation influence on the interannual variability of snowpack in the Spanish Pyrenees during the second half of the twentieth century. Nordic Hydrology, 38: 33-44.

López-Moreno JI, Beguería S, Vicente-Serrano SM, García-Ruiz JM. 2007. The Influence of the NAO On Water Resources In Central Iberia: Precipitation, Streamflow Anomalies And Reservoir Management Strategies. Water Resources Research. W09411 doi: 10.1029/2007WR005864.

López-Moreno JI, Vicente-Serrano SM. 2008. Extreme phases of the wintertime North Atlantic Oscillation and drought occurrence over Europe: a multi-temporal-scale approach. Journal of Climate 21: 1220-1243. 
Madsen H, Rosbjerg D. 1997. The partial duration series method in regional index-flood modeling, Water Resources Research 33: 737-746.

Martín-Vide J. 2004. Spatial distribution of a daily precipitation concentration index in Peninsular Spain. International Journal of Climatology, 24: 959-971.

Martin-Vide J, Lopez-Bustins JA. 2006. The Western Mediterranean Oscillation and rainfall in the Iberian Peninsula. International Journal of Climatology 26: 14551475.

Martín-Vide J, Sánchez-Lorenzo A, López-Bustins JA, Cordobilla MJ, García-Manuel A, Raso JM. 2008. Torrential Rainfall in Northeast of the Iberian Peninsula: Synoptic patterns and WeMO influence. Advances in Science and Research 2: 99-105.

McBratney A, Mendonça-Santos M, Minasny B. 2003. On digital soil mapping. Geoderma 117: 3-52.

Mitasova H, Mitas L. 1993. Interpolation by regularized Spline with tension. Mathematical Geology 25: 641-655.

Ninyerola M, Pons X, Roure JM. 2007. Objective air temperature mapping for the Iberian Peninsula using spatial interpolation and GIS. International Journal of Climatology 27: 1231-1242.

Palutikof JP. 2003. Analysis of Mediterranean climate data: measured and modelled. In: Bolle, H.J. (ed): Mediterranean climate: Variability and trends. SpringerVerlag, Berlin

Peñarrocha D, Estrela, MJ, Millán M. 2002. Classification of daily rainfall patterns in a Mediterranean area with extreme intensity levels: the Valencia region. International Journal of Climatology 22: 677-695.

Phillips ID, McGregor GR. 2001. The relationship between synoptic scale air ow direction and daily rainfall: a methodology applied to Devon and Cornwall, South West England. Theoretical and Applied Climatology, 69: 179-198.

Pons X, Ninyerola M. 2008. Mapping a topographic global solar radiation model implemented in a GIS and refined with ground data. International Journal of Climatology.

Prudhome C, Reed DW. 1999. Mapping extreme rainfall in a mountainous region using geostatistical techniques: A case study in Scotland. International Journal of Climatology 19: 1337-1356.

Rao AR, Hamed KH. 2000. Flood Frequency Analysis. CRC Press.

Rodó X, Baert E, Comín FA. 1997. Variations in seasonal rainfall in southern Europe during the present century: relationships with the North Atlantic Oscillation and the El Niñoo-Southern oscillation. Climate Dynamics 13: 275-284.

Rodrigo FS, Trigo RM. 2007. Trends in daily rainfall in the Iberian Peninsula from 1951 to 2002. International Journal of Climatology 27: 513-529.

Rodríguez-Puebla C, Encinas AH, Sáenz J. 2001. Winter precipitation over the Iberian peninsula and its relationship to circulation indices. Hydrology and Earth System Sciences 5: 233-244.

Santos JA, Corte-Real J, Leite SM. 2005. Weather regimes and their connection to the winter rainfall in Portugal. International Journal of Climatology 25: 33-50.

Santos JA, Corte-Real J, Ulbrich U, Palutikof J. 2007. European winter precipitation extremes and large-scale circulation: A coupled model and its scenarios. Theoretical and Applied Climatology 87: 85-102.

Scaife AA, Folland CK, Alexander LV, Moberg A, Knight JR. 2008. European climate extremes and the North Atlantic Oscillation. Journal of Climate 21: 72-83. 
Svensson C, Jakob D, Reed D. 2002. Diurnal characteristics of heavy precipitation according to weather type at an upland site in Scotland. International Journal of Climatology 22: 569-585.

Thompson DWJ, Wallace JM. 2001. Regional climate impacts of the Northern Hemisphere annular mode. Science 293: 85-89.

Trigo RM, Palutikof JP. 2001. Precipitation scenarios over Iberia. A comparison between direct GCM output and different downscaling techniques. Journal of Climate 14: 4422-4446.

Twardosz R, Niedzwiedz T. 2001. Influence of synoptic situations on the precipitation in Krakow (Poland). International Journal of Climatology 21: 467-481 (2001).

UCAR/NCAR/CISL/DSS, DOC/NOAA/NWS, MIT/EAPS, GB/MOD/MET, DOC/NOAA/NESDIS/NCDC, DOD/USNAVY/NRL/MRY and DOC/NOAA/NWS/NCEP. 1979. Daily Northern Hemisphere Sea Level Pressure Grids, continuing from 1899, updated monthly. Published by the CISL Data Support Section at the National Center for Atmospheric Research, Boulder, $\mathrm{CO}(\mathrm{ds} 010.0)$.

Van der Schrier G, Briffa KR, Jones PD, Osborn TJ. 2006. Summer moisture variability across Europe. Journal of Climate 19: 2818-2834.

Vicente Serrano SM, López-Moreno JI. 2006. The influence of atmospheric circulation at different spatial scales on winter drought variability through a semiarid climatic gradient in north east Spain. International Journal of Climatology 26: 1427-1456.

Vicente-Serrano SM, Lanjeri S, López-Moreno JI. 2007. Comparison of different procedures to map reference evapotranspiration using geographical information systems and regression-based techniques. International Journal of Climatology 27: 1103-1118.

Wallace JM, Gutzler DS. 1981. Teleconnections in the geopotential height field during the Northern Hemisphere winter. Monthly Weather Review 109: 784-812.

Wanner, H. et al. (2001), North Atlantic Oscillation - Concepts and studies. Surveys in Geophysics 22, 321-382.

White S, Garcia-Ruiz JM, Marti C, Valero B, Errea MP, Gómez-Villar A. 1997. The 1996 Biescas Campsite disaster in the Central Spanish Pyrenees, and its temporal and spatial context. Hydrological Processes 11: 1797-1812.

Yarnal B, Comrie AC, Frakes B, Brown DP. 2001. Developments and prospects in synoptic climatology. International Journal of Climatology 21: 1923-1950. 


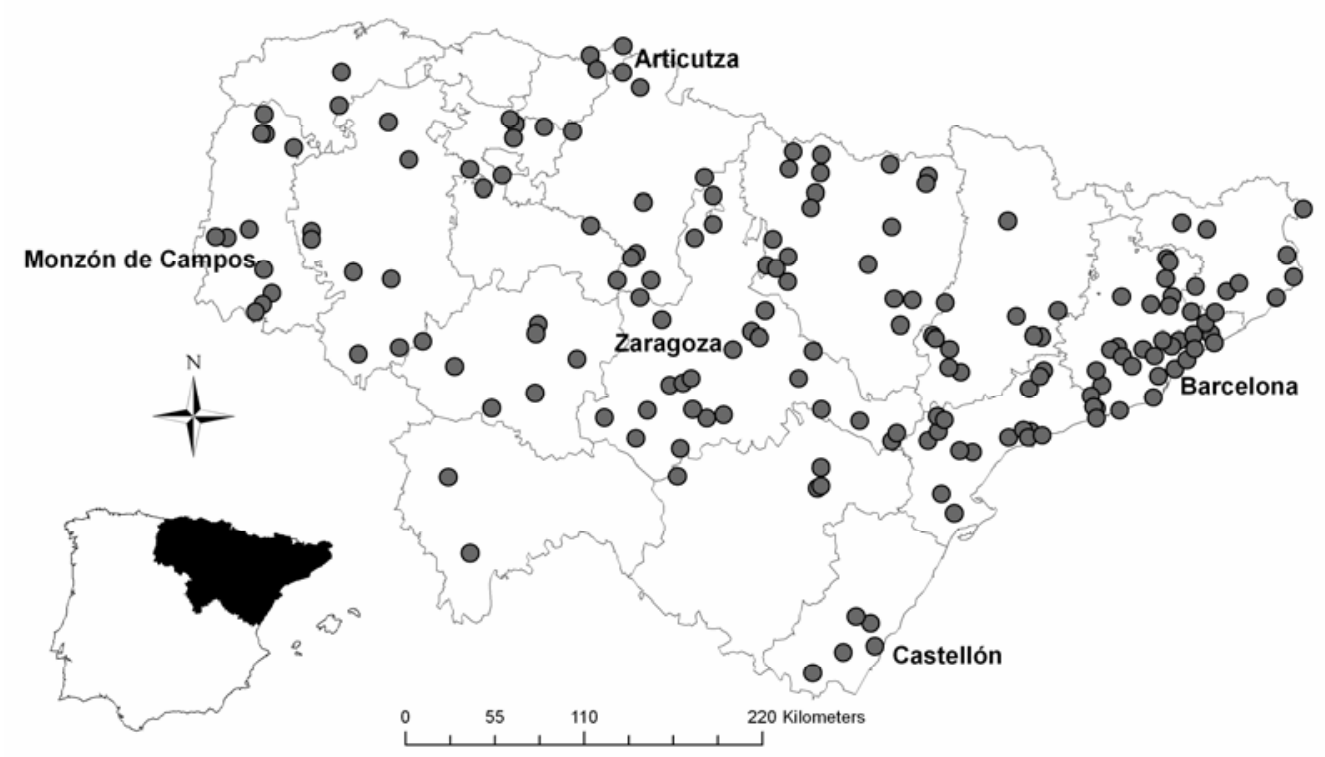

Figure 1. Spatial distribution of the daily precipitation observatories considered in the present study (data for the period 1950-2006). The named observatories are those considered in greatest depth throughout the paper. 


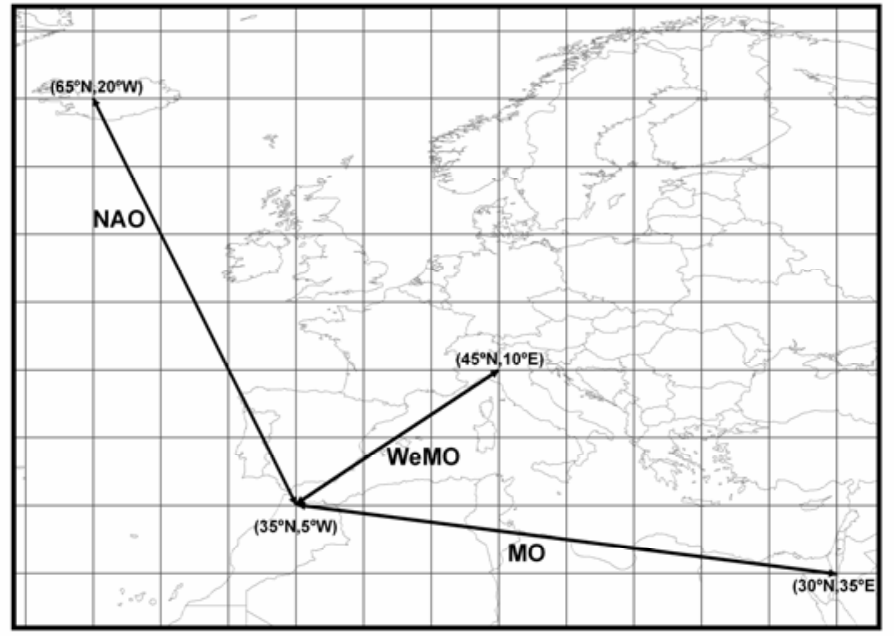

Figure 2. Sea-level-pressure points used to calculate the daily atmospheric circulation indices. 


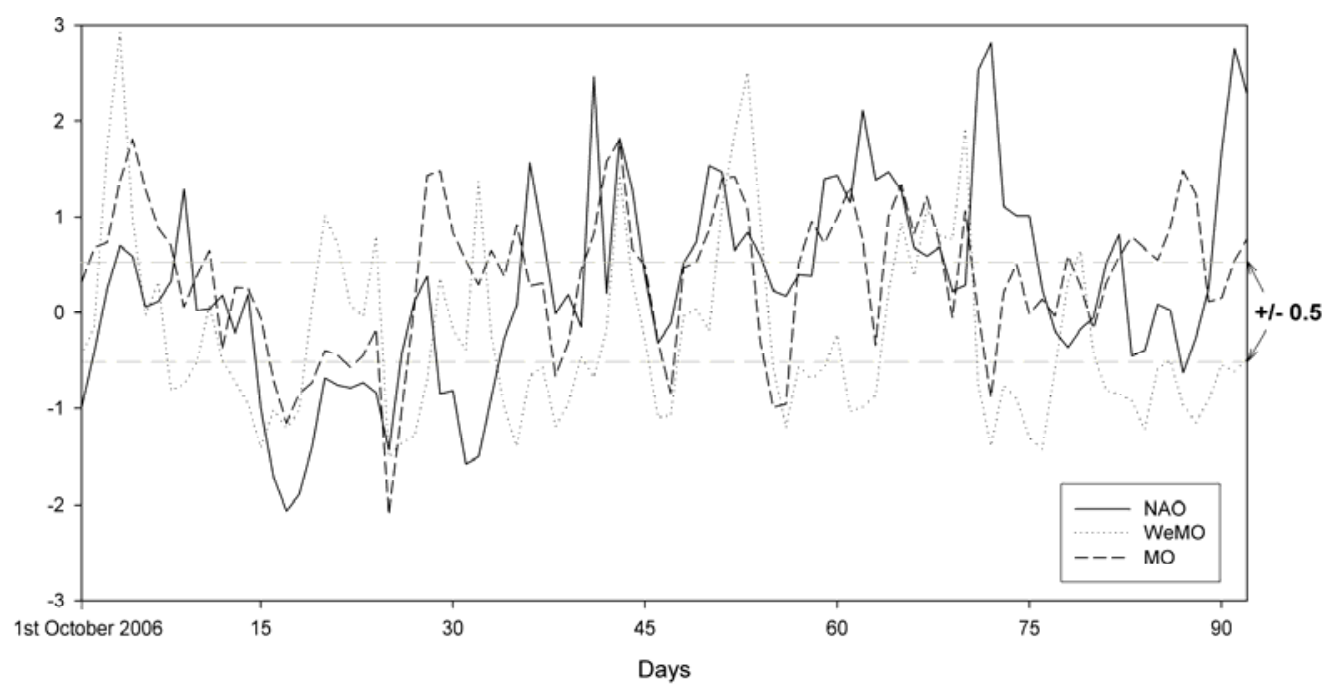

Figure 3. Temporal evolution of daily NAO, WeMO, and MO indices between 1 October 2006 and 31 December 2006. 

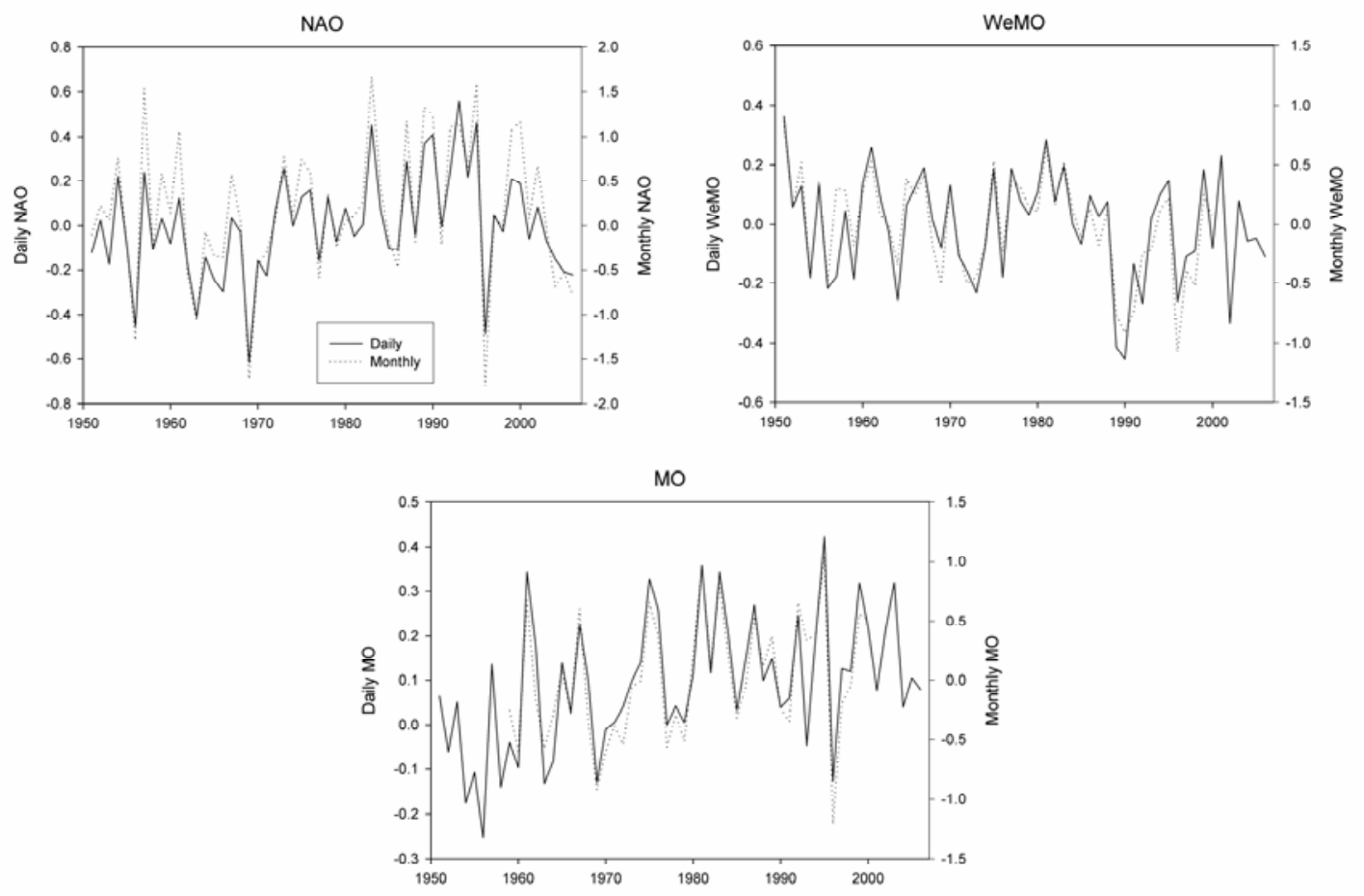

Figure 4. Temporal evolution of October-March WeMO, NAO, and MO indices obtained from average daily and monthly indices. 

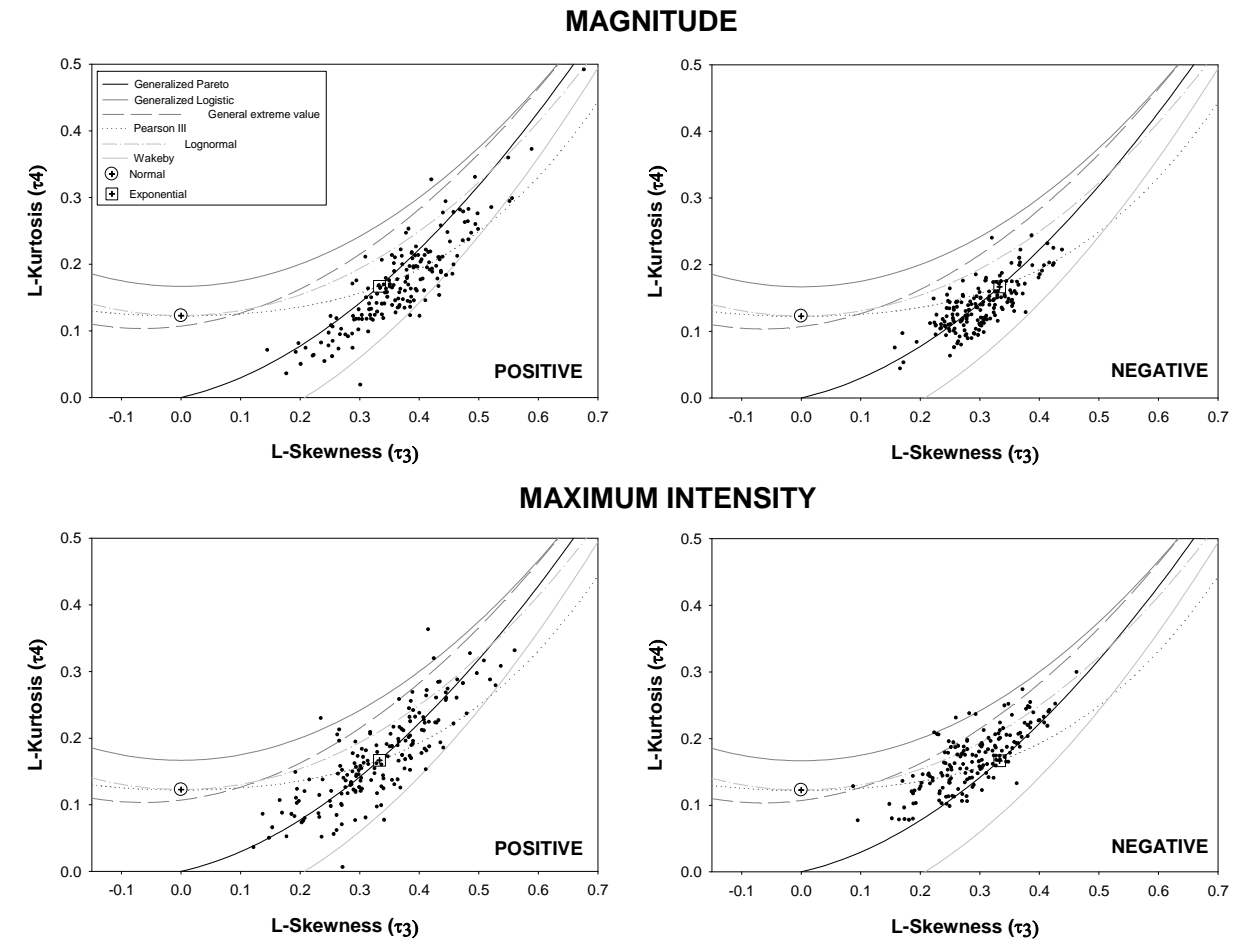

Figure 5. L-Moment diagrams for series of the magnitude and maximum intensity of precipitation for positive and negative NAO events. Each point indicates the statistics for each observatory. 
MAGNITUDE
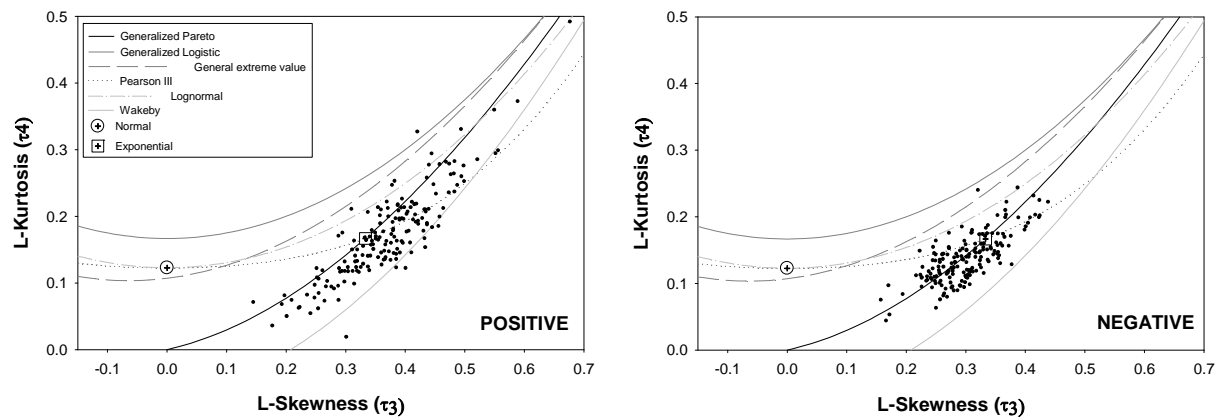

MAXIMUM INTENSITY
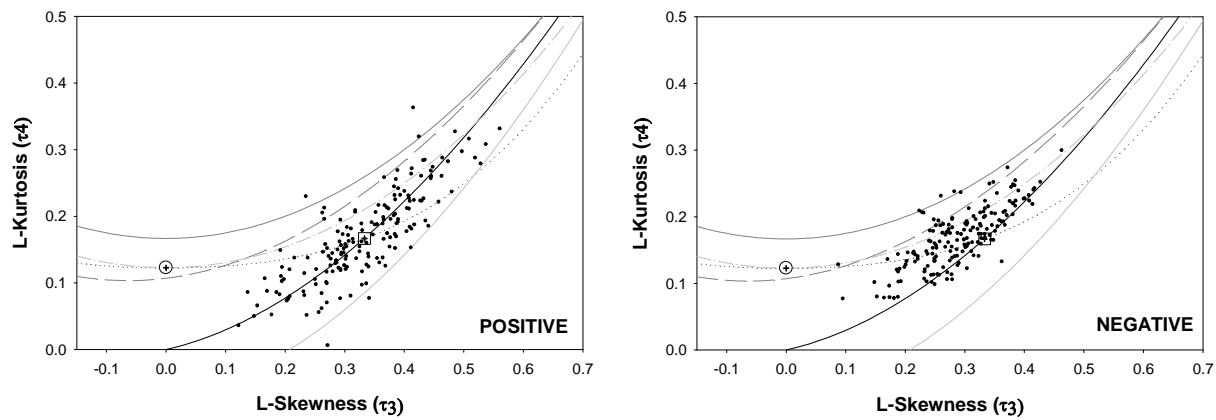

Figure 6. L-Moment diagrams for series of the magnitude and maximum intensity of precipitation for positive and negative WeMO events. Each point indicates the statistics for each observatory. 
MAGNITUDE
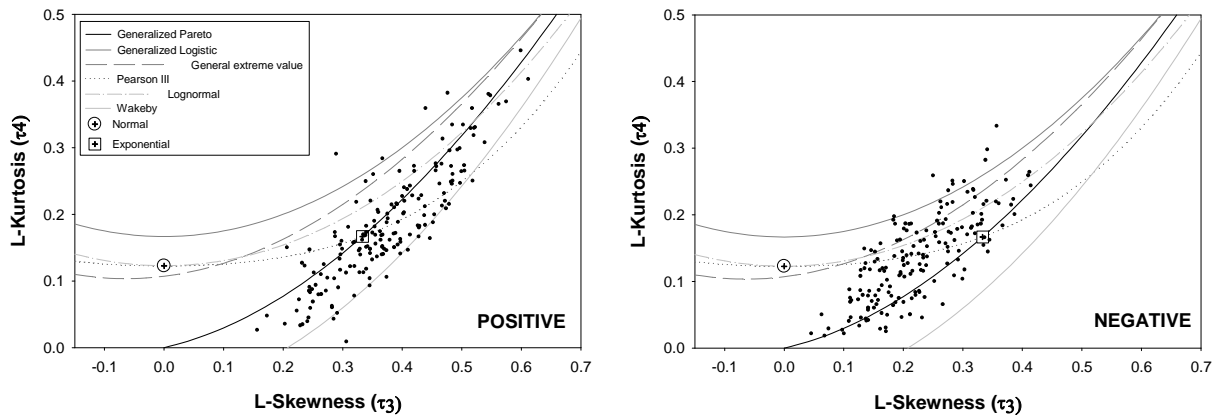

MAXIMUM INTENSITY
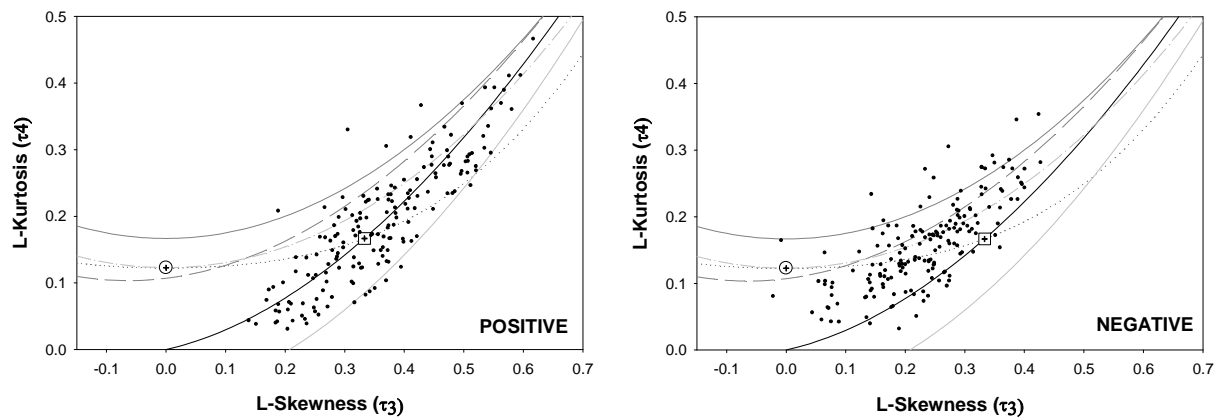

Figure 7. L-Moment diagrams for series of the magnitude and maximum intensity of precipitation for positive and negative MO events. Each point indicates the statistics for each observatory. 

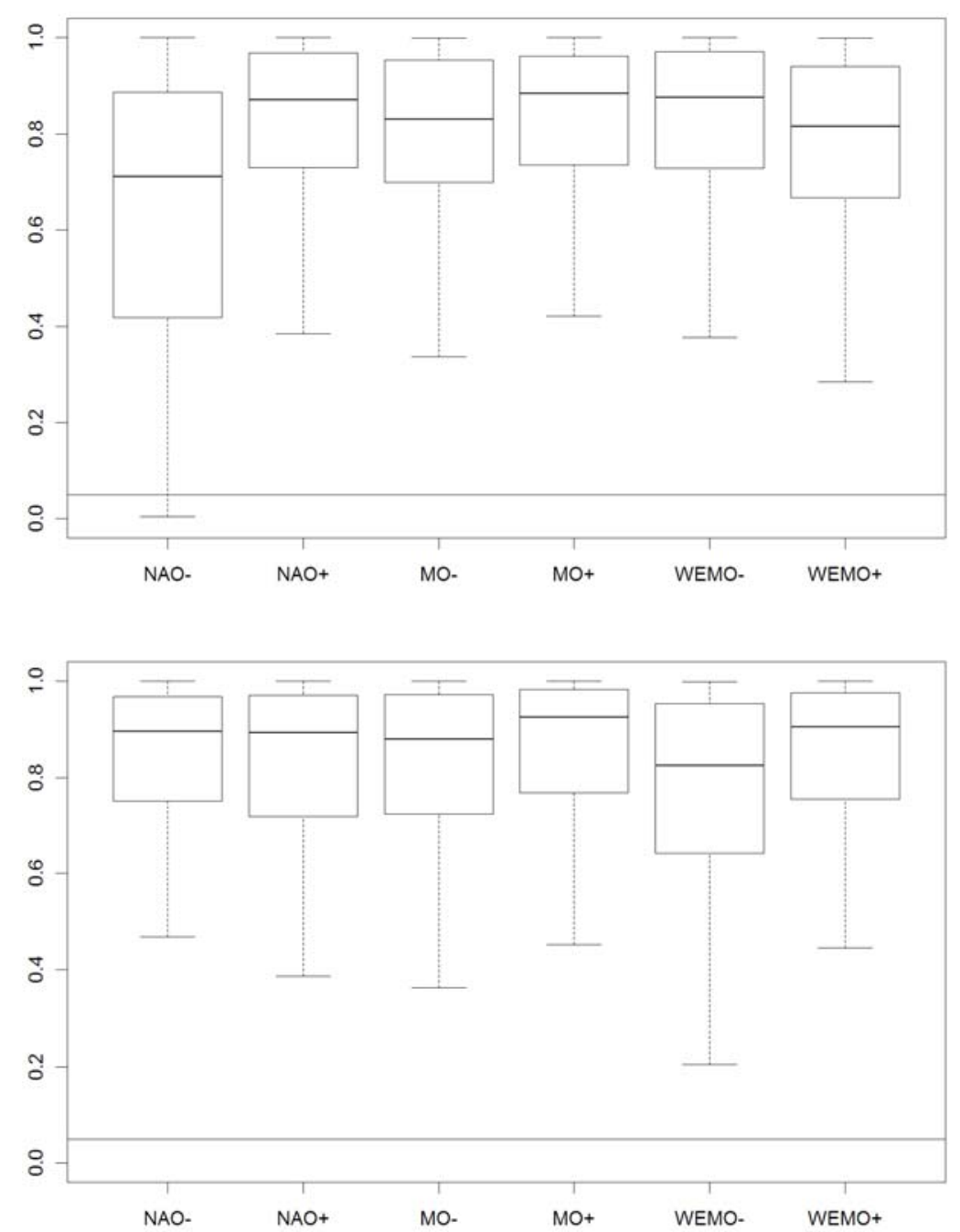

Figure 8. Box-plot of the p-values obtained from the Kolmogorov-Smirnov test. Above: precipitation intensity. Below: precipitation magnitude. 
* significant at $\alpha=0.05$

Table 1. Values of the dispersion index (DI, ratio between the variance and the average occurrences per year) of the event series defined by different atmospheric circulation indices. 
a)
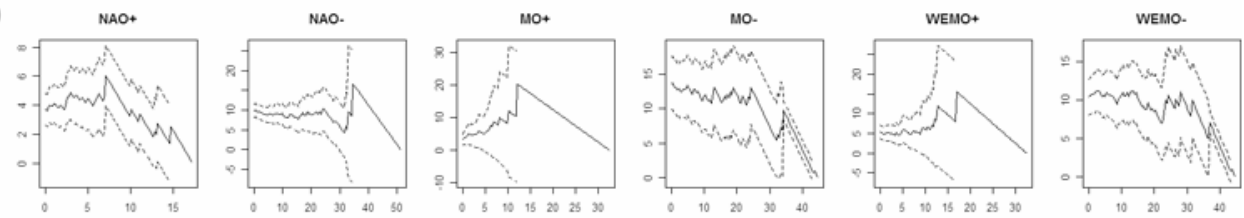

b)
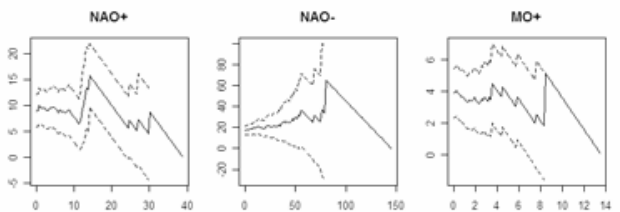

MO.

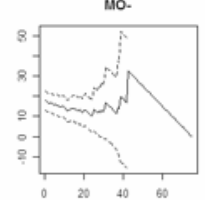

พЕм⿰о

WEMO
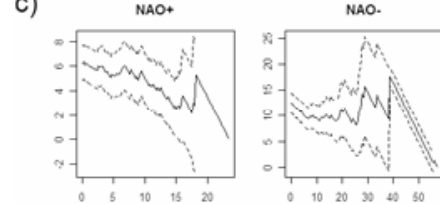

MO+
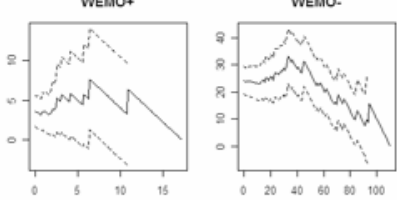

mo.

WEMO+

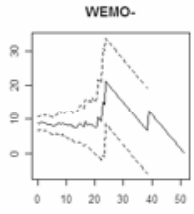

d)
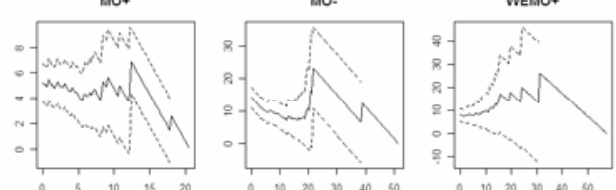

WEIN
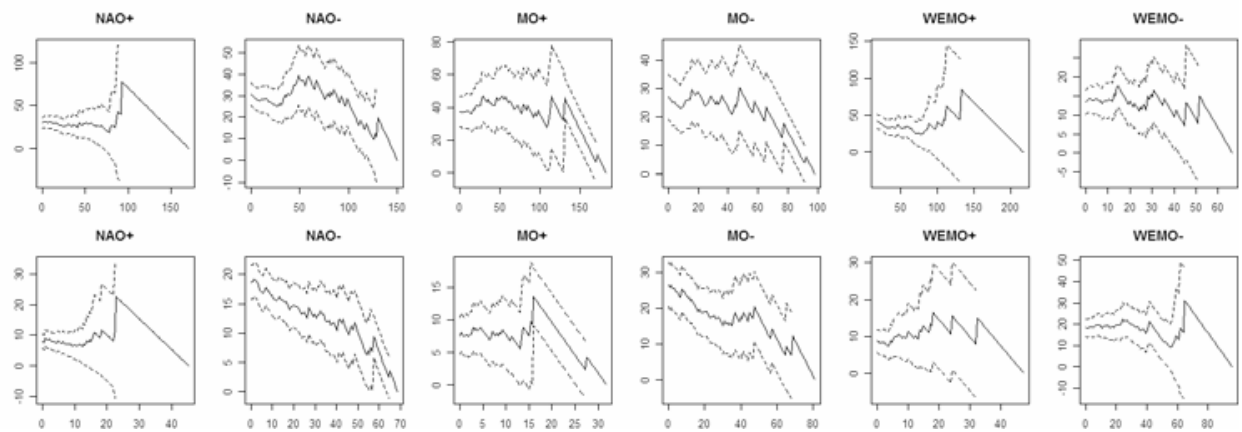

Figure 9. Mean residual life plots for the events intensity and different atmospheric circulation patterns. The following observatories are shown as an example: a) Zaragoza; b) Castellón; c) Monzón de Campos; d) Articutza; e) Barcelona. 


\begin{tabular}{ll}
\hline LAT & Latitude $(\mathrm{km})$ \\
LONG & Longitude $(\mathrm{km})$ \\
D_SEA & Joint Distance to the Mediterranean Sea and the Atlantic Ocean $(\mathrm{km})$ \\
D_MED & Distance to Mediterranean Sea $(\mathrm{km})$ \\
D_ATL & Distance to Atlantic Ocean $(\mathrm{km})$ \\
ELEV & Elevation $(\mathrm{m})$ \\
ELEVx & Average elevation $(\mathrm{m})$ within $x$, where $x$ is a circular window with radii of $2.5,5$, and $25 \mathrm{~km}$ \\
RAD & Annual average incoming solar radiation $(\mathrm{MJ} \times$ day) \\
RADx & Annual average incoming solar radiation $(\mathrm{MJ} \times$ day) within $x$, where $x$ is a circular window with radii of \\
SLOPE & $2.5,5$, and $25 \mathrm{~km}$ \\
SLOPEx & Alope gradient $(\%)$ \\
\hline
\end{tabular}

Table 2. List of independent geographic and topographic covariates employed in regression-based interpolation. 


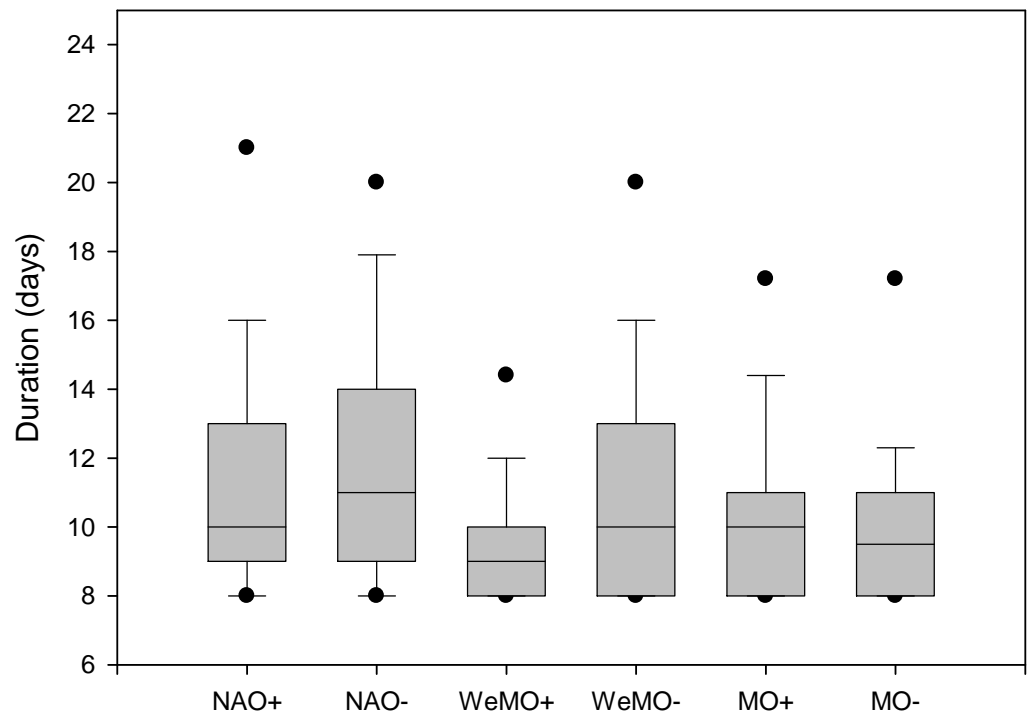

Figure 10. Boxplot of event duration (in days) for positive and negative phases of the three atmospheric circulation indices. 

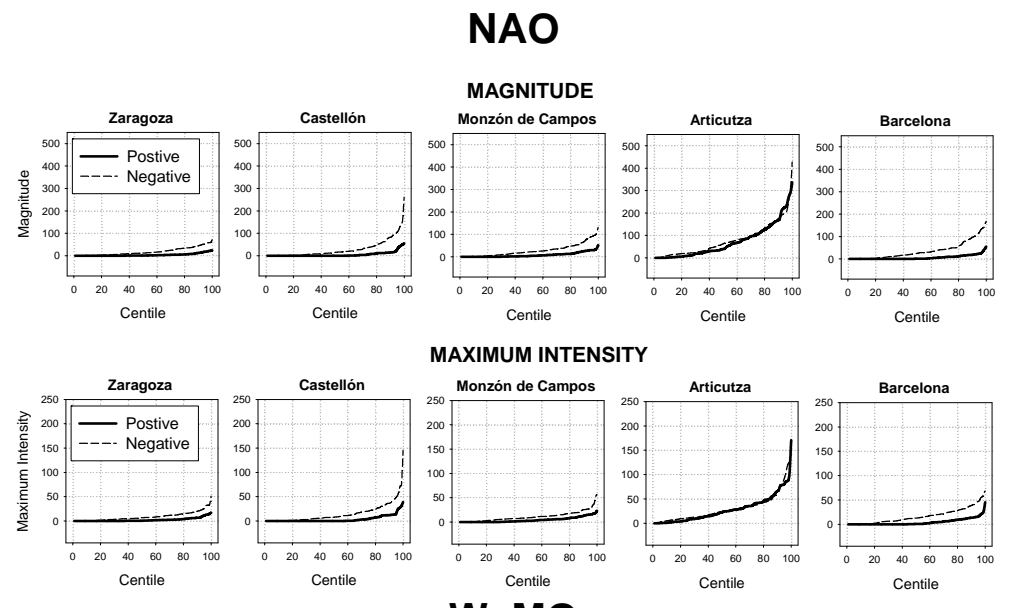

WeMO
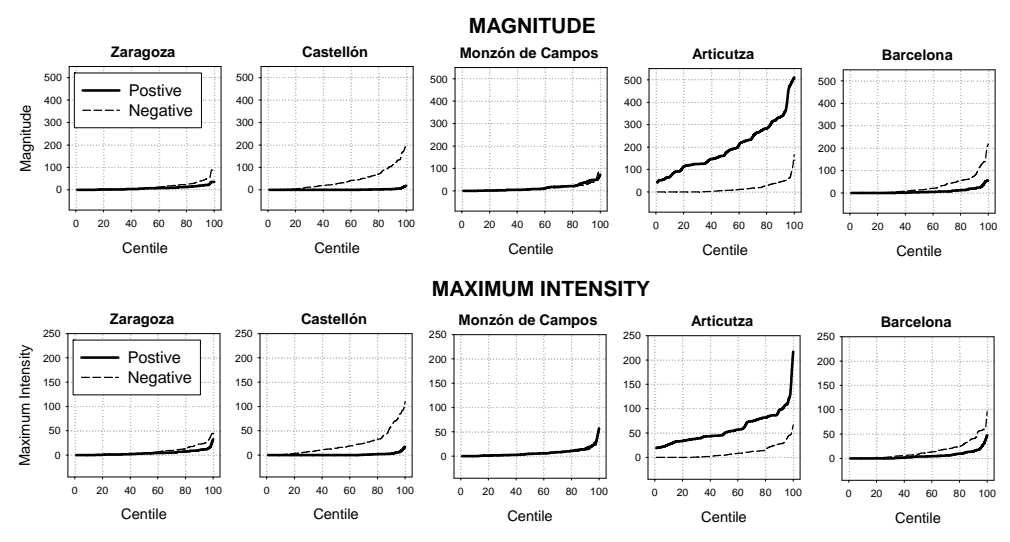

MO
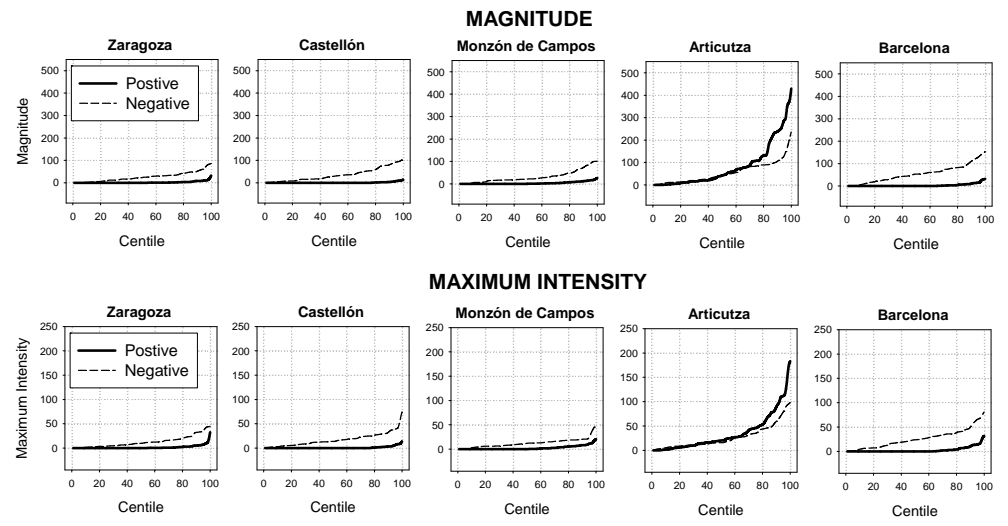

Figure 11. Centile values of precipitation magnitude and maximum intensity for positive and negative $\mathrm{NAO}$, WeMO and $\mathrm{MO}$ events for five representative observatories. 
a)

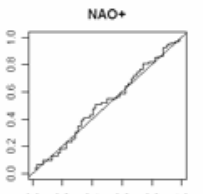

b)

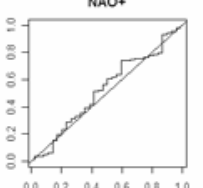

c)

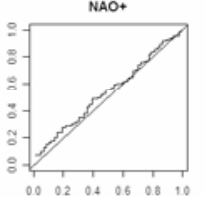

d)

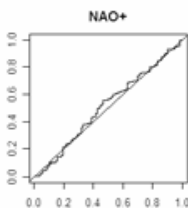

e)

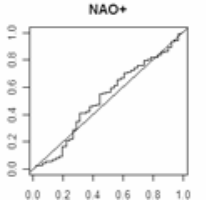

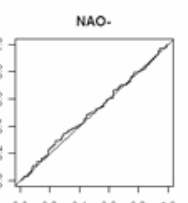

NAO.

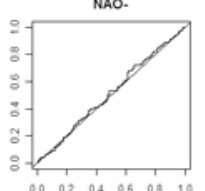

NAO.

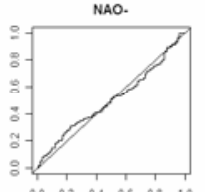

NAO.

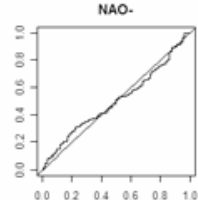

NAO.

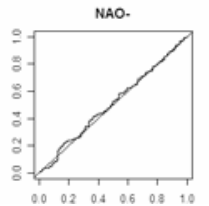

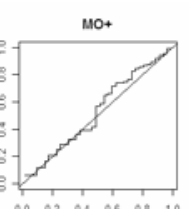

MO+

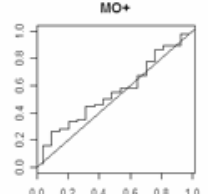

MO+

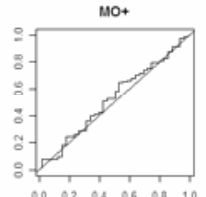

$\mathrm{MO}+$

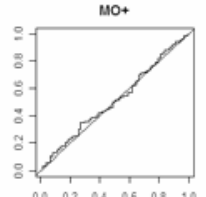

MO+

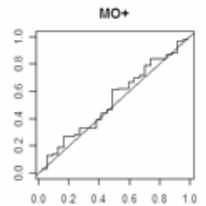

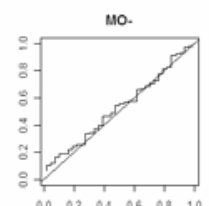

Mo-

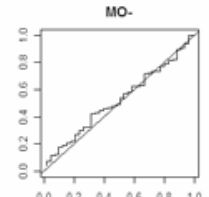

mo.

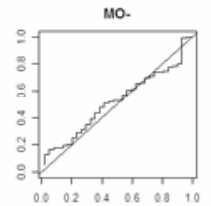

мо.

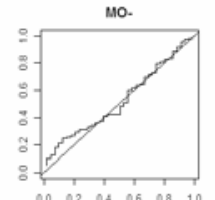

mo.

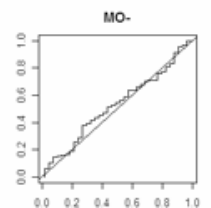

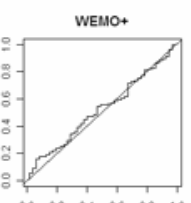

WEMO+

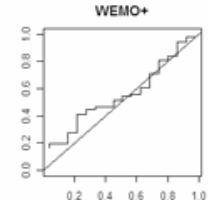

WEMO+

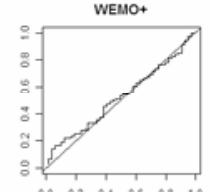

WEMO+

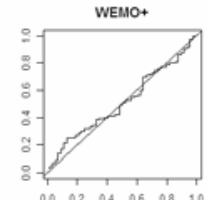

WEMO+

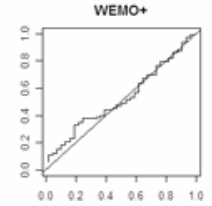

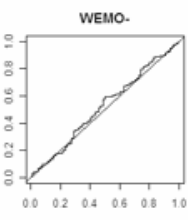

WEMO-

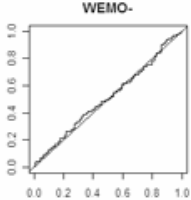

WEMO

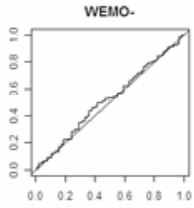

WEMO.

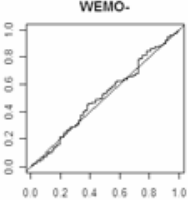

WEMO.

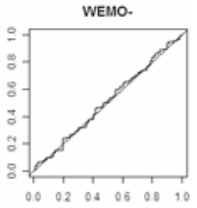

Figure 12. pp-plots between the empirical distribution and the modeled Generalised Pareto distribution for precipitation intensity series in five representative observatories corresponding to the positive and negative phases of the three atmospheric circulation patterns. a) Zaragoza; b) Castellón; c) Monzón de Campos; d) Articutza; e) Barcelona. 
Maximum Intensity NAO- $\alpha$

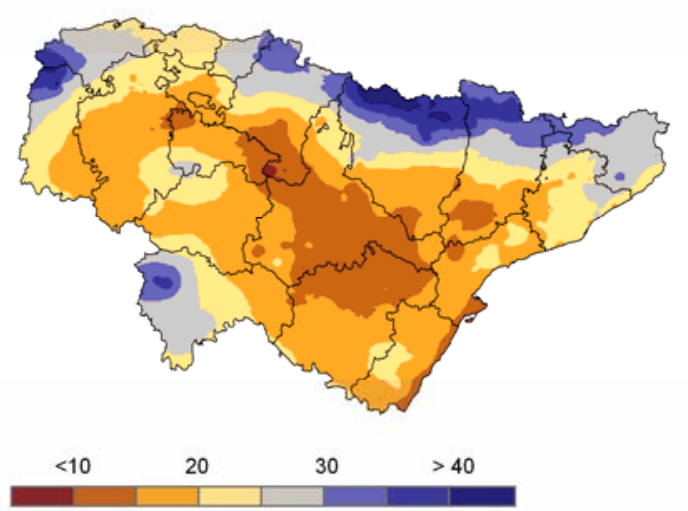

Magnitude $\mathrm{WeMO}+\lambda$

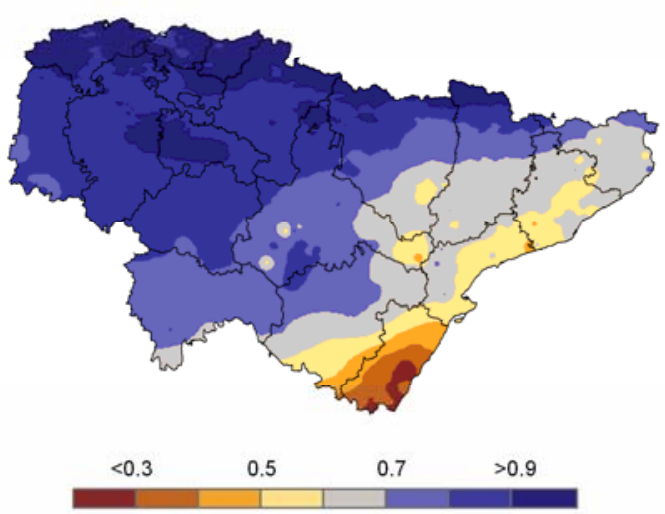

Figure 13. Example of the spatial distribution of GP parameters throughout the study area. 

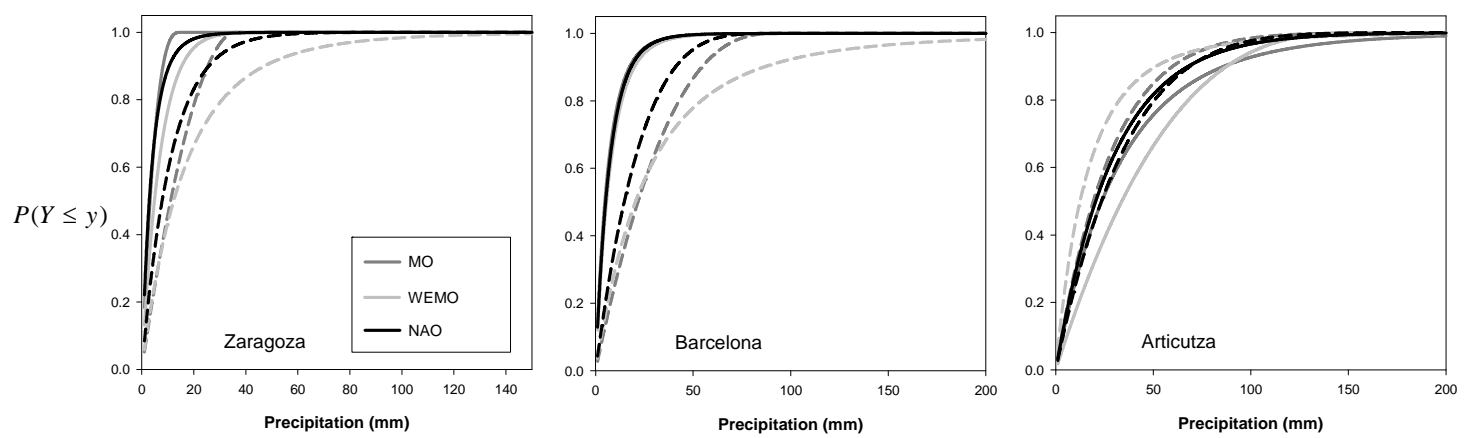

Figure 14. Non-exceedance probability curves corresponding to the maximum intensity of precipitation recorded during positive and negative NAO, WeMO, and MO events at the Zaragoza, Barcelona and Articutza observatories. Dashed lines: negative events; solid lines: positive events. 


\section{MAXIMUM INTENSITY > $50 \mathrm{~mm}$}

NAO

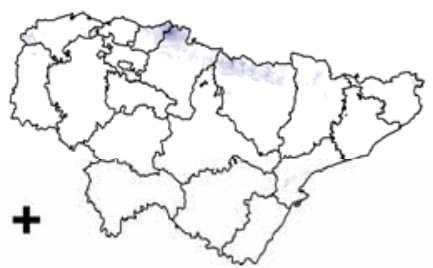

WEMO

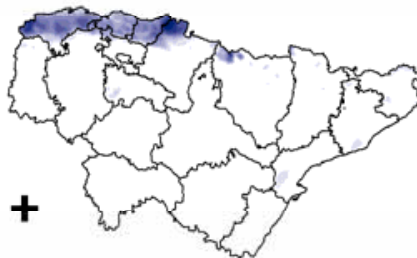

MO

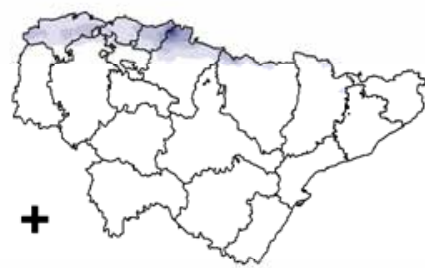

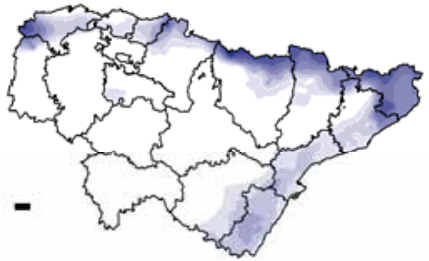
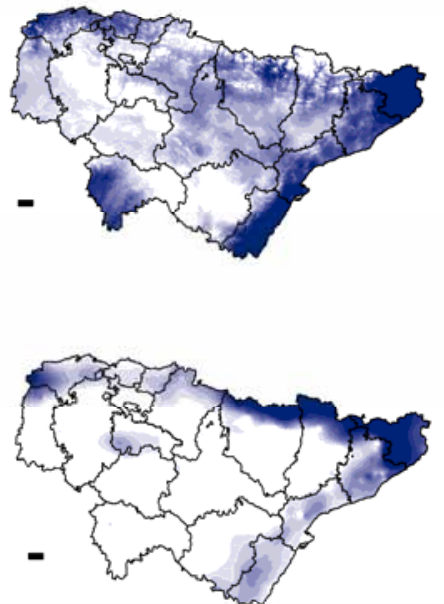

$<3 \%$

$9 \%$
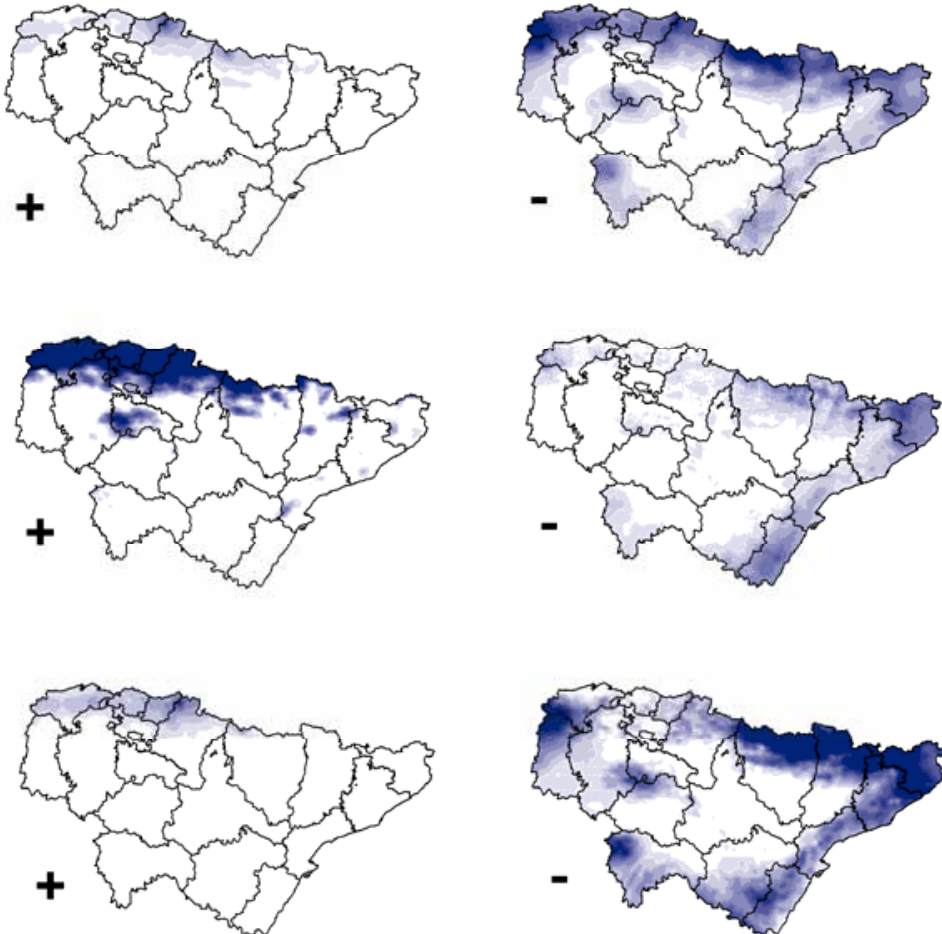

$21 \%$

Figure 15. Probability of maximum intensity of precipitation exceeding $50 \mathrm{~mm}$ and total magnitude exceeding $100 \mathrm{~mm}$ corresponding to positive and negative NAO, WeMO, and MO events following a GP distribution. 


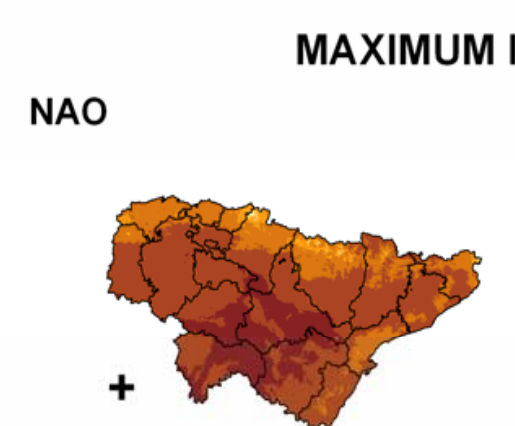

WEMO

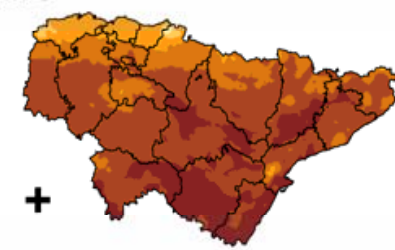

MO

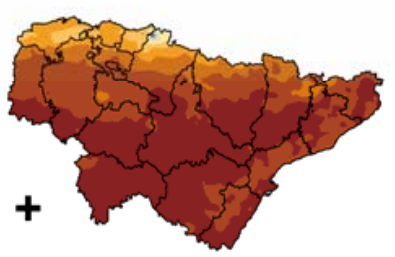

20
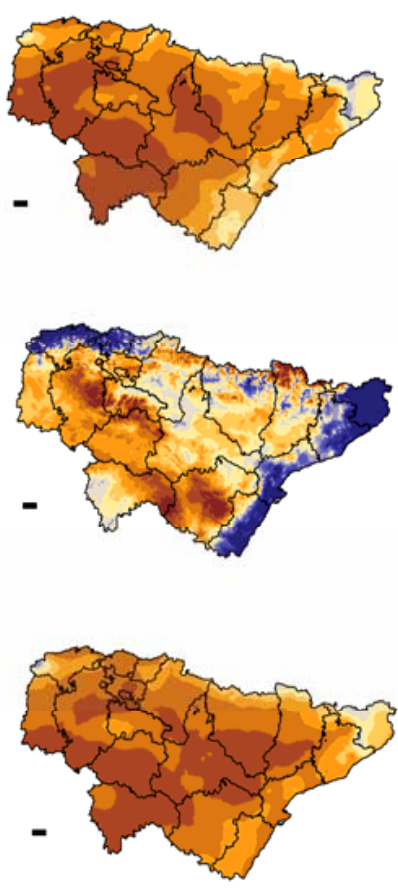

$-$
MAGNITUDE
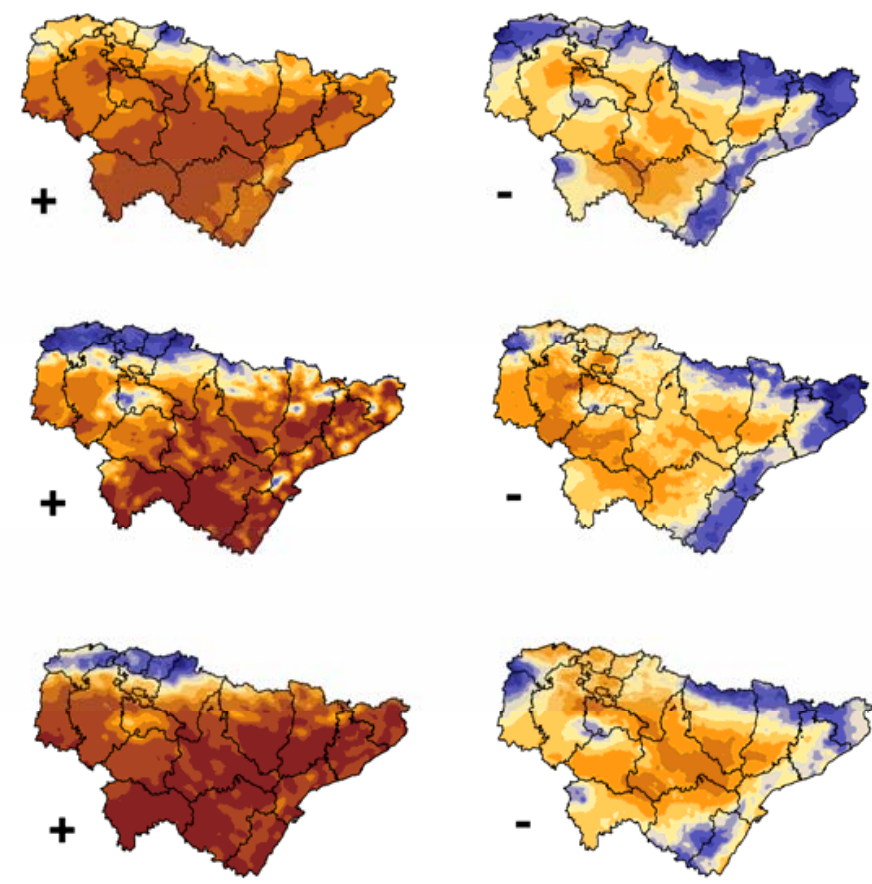

$\begin{array}{llllll}25 & 75 & 125 & 175 & 250 & 350\end{array}$

Figure 16. Quantile maps of maximum daily precipitation and total magnitude during NOA, WeMO, and MO events corresponding to a return period of 50 years. 